\title{
Un análisis en perspectiva histórica del comercio exterior de las autopartes argentinas
}

\section{A historical analysis of the Argentine autoparts foreign trade}

\author{
Damián Andrés Bil \\ Centro de Estudios Urbanos y Regionales (CEUR), CONICET \\ http://orcid.org/0000-0002-7054-2927 \\ damianbil@conicet.gov.ar
}

Fecha de recepción: 3 de febrero de 2014

Fecha de aprobación: 15 de julio de 2014

Sugerencia de citación: Bil, D. (2015). Un análisis en perspectiva histórica del comercio exterior de las autopartes argentinas. tiempo\&economía, 2(1), 111-135.

\section{Resumen}

La industria automotriz argentina es uno de los sectores más estudiados por la historia económica. Sus límites se atribuyen a la mayor o menor intervención del Estado, al legado del neoliberalismo o a las estrategias de las multinacionales. A nuestro entender, estas aproximaciones dejan de lado el análisis de las condiciones de producción tanto internas como en el mercado mundial. Como un paso para ampliar estas explicaciones, analizamos la balanza comercial de autopartes argentinas en perspectiva histórica, con el objeto de entender los problemas históricos del complejo en Argentina. 
Palabras clave: Estudios de comercio, estructura industrial en América Latina estructura industrial, desarrollo industrial, automotriz.

Códigos JEL: F14, N16, L16, O14, L62

\section{Abstract}

The Argentine automotive industry is one of the most studied topics in economic history. The authors explain their limits by the state intervention, the legacy of neoliberalism or the strategies of multinationals. These approaches neglect the analysis of production conditions, internally and on the world market. As a step to extend these explanations, we analyze the trade balance of the Argentine auto parts industry in historical perspective, in order to understand the problems of the automotive complex in Argentina.

We analyze the Argentina autoparts trade balance in the last 20 years, in order to understand the deficits of the automotive industry.

Keywords: Empirical studies of trade, Industrial structure - Latin America, Industrial Structure, Industrialization, automobiles.

JEL Codes: F14, N16, L16, O14, L62 


\section{Introducción}

El sector automotor es una vía de entrada privilegiada para estudiar la industria en un espacio nacional determinado. Por un lado, es un indicador del grado de avance que alcanzó esa estructura. Por el otro, al poner en vinculación una serie de procesos, permite abordar las condiciones fundamentales de lo que se conoce como cadenas de valor. Es decir, de diferentes eslabones de la producción manufacturera de un país y su inserción en el mercado mundial.

En este marco, en Argentina el sector es señalado desde esferas oficiales como la punta de lanza de un supuesto "nuevo modelo productivo". Las estadísticas de los últimos años, en los que se consiguieron volúmenes de producción récords, alimentaron esa euforia. La devaluación luego de 2001, la caída del costo laboral y del salario y la posibilidad del Estado de subsidiar al sector gracias a los precios agrarios en alza provocaron un repunte en la actividad en relación con la década previa. No obstante, una mirada más detenida de la situación nos muestra ciertos inconvenientes. Si bien las terminales consiguieron ventas y ganancias récords, el saldo del complejo continúa, como en la mayor parte de su historia, en déficit. En particular, por la necesidad creciente de importación de autopartes. Esta cuestión pone en duda la supuesta recuperación del sector y su liderazgo como uno de los aparentes motores de la economía argentina. En este trabajo nos proponemos analizar la balanza comercial de la actividad en el país, con el fin de entender si la situación actual muestra diferencias con su recorrido histórico, o bien, reproduce sus mismos problemas. En ese punto, también intentaremos comprender si los déficits se deben a la falta de políticas adecuadas o si están manifestando límites estructurales de la economía argentina.

Con este primer análisis, buscamos aportar elementos al debate sobre el desarrollo industrial en América Latina, en particular en Argentina.

\section{Estado de la cuestión y antecedentes}

El complejo automotor en Argentina fue analizado por varios autores desde diferentes perspectivas (Remes Lenicov, 1974; Sourrouille, 1980; Lifschitz, 1982; Kosacoff, Todesca et al., 1991; Frenkel, 1992; Belini, 2006; Barbero y Motta, 2007; lanni, 2008). En estos trabajos se condensaba una serie de problemáticas claves en los debates sobre el período: articulación entre capital extranjero y nacional y entre grandes y chicos, problemas de transferencia y adaptación de tecnología, existencia de mecanismos de intervención estatal en forma directa e indirecta, entre otros. En este derrotero, al tratarse de una producción sujeta a una gran cantidad de proveedores de diferente complejidad, el autopartismo es clave para explicar su evolución. No obstante, la industria de autopartes fue poco estudiada. Se destacan estudios de caso particulares (Soria, 1989; Moori-Koenig y Yoguel, 1992; Oliber, 1995; Roldán, 2000; Romano et al., 2002; Maceira, 2003; Motta et al., 2007; Cantarella et al., 2008; García Garnica, 2008; Novick et al., 2009) o informes técnicos oficiales (Britos y Fidel, 1989), aunque, a nuestro entender, queda pendiente una reconstrucción de las condiciones generales de acumulación en la rama autopartista.

Algunos autores ponen en evidencia este desfase entre la industria terminal y el autopartismo en los últimos veinte años. Por lo general, atribuyen esa problemática a una cuestión 
de "políticas". El legado del neoliberalismo, que habría profundizado la "desindustrialización" iniciada a finales de los años setenta, sería el principal factor que impide un crecimiento virtuoso del complejo. Ello provocaría que las políticas actuales sean insuficientes para corregir el devenir de la actividad (Manzanelli y Castells, 2013). O bien, que se encuentren encaminadas, aunque falten detalles por desarrollar (Novick et al., 2009). Otros señalan que los inconvenientes radican en factores diversos, como el reducido grado de protección, la incertidumbre y las fallas de mercado; lo que generó límites en la radicación de inversiones, en la capacidad de acumulación y en el grado de "confianza y respeto en las negociaciones cliente-proveedor" (Cantarella et al., 2008, p. 39). Manzanelli y Castells agregan que las estrategias de las multinacionales en la nueva división del trabajo descartan a la región como una plataforma de producción de autopartes, lo que profundiza esta dificultad.

En definitiva, los autores sostienen que la mayor parte de los problemas son solucionables con mejor voluntad política y empresarial, o con mejores decisiones o ajustes en lo ya realizado. La dificultad de estas aproximaciones es que no ponderan la situación actual de la rama en términos históricos. Por ese motivo, no pueden discriminar entre dificultades coyunturales y la reiteración de problemas estructurales de la industria argentina en sus encadenamientos básicos. En segundo lugar, presentan indicadores de la actividad, pero abstraídos de la competencia internacional. Es decir, pierden de vista la situación del mercado mundial. El aumento de las ventas, de las exportaciones, o incluso de la productividad, no explica nada escindido del movimiento del resto del capital en la rama.

Por ello, consideramos que la mayoría de los estudios tienen un déficit que limitó en parte las respuestas brindadas. Por lo general, se concentraron en la evolución de la economía en términos exclusivamente nacionales. Con ello, no entienden que la acumulación de capital es parte de una dinámica general, aun con sus especificidades. Se omite el análisis del mercado mundial, marco en el cual se desarrolla la acumulación en Argentina. La competencia internacional es un elemento que falta ponderar para entender las particularidades de la industria en el país.

En este trabajo planteamos un primer paso en ese sentido. Nos proponemos analizar la balanza comercial de autopartes de Argentina, con atención a lo sucedido desde la conformación del Mercosur, en 1991. Esa aproximación nos brindará un panorama de la situación actual del complejo, y también de sus déficits. Pero el estudio no puede completarse sin revisar en términos históricos el devenir de la producción de automóviles y autopartes. Como mencionamos, eso posibilitará determinar si los problemas actuales son fruto de una coyuntura específica, o bien, son expresión de los límites del sector y de las relaciones sociales que lo sustentan. Esta segunda explicación es lo que se constituye como nuestra hipótesis de trabajo.

El objetivo de largo plazo de la investigación es entender cómo sobrevive en Argentina un sector automotor conformado por terminales y autopartistas que son menos productivos que los capitales rectores de la actividad en el ámbito mundial; y que, por ende, necesitan compensar su menor competitividad con transferencias desde el Estado. Por eso, buscamos determinar cuál es la magnitud de lo que hay que transferir al sector, debido a su ineficiencia en relación con los líderes mundiales. En otras palabras, explicar los costos y consecuencias de la protección del mercado y, encadenado a ello, la pervivencia del pequeño capital. En esa investigación de largo plazo, este documento se plantea como uno de los primeros pasos necesarios para ese objetivo. 
A partir de estadísticas de organismos internacionales y locales, reconstruimos la balanza automotriz y de autopartes argentinas en sus principales productos. Con ello, buscamos ponderar los sectores deficitarios de la balanza y plantear algunas explicaciones sobre ese particular.

Consideramos que esta primera aproximación servirá para identificar las bases de la actividad en los últimos años, con la intención de profundizar en el conocimiento de este sector en futuros trabajos.

\section{El sector autopartista en la etapa del mercado protegido (1960-1990)}

\section{a. El mercado mundial. Principales productores y exportadores}

Luego de la Segunda Guerra Mundial, la producción automotriz recuperó su impulso. Se abrieron fábricas en diferentes países, tanto en los tradicionales como en los que comenzaban a consolidar un complejo automotor (Argentina, Brasil, México, Irán, India, y otros). No obstante, a pesar de la expansión de la actividad hacia otras regiones, los países líderes continuaron con el mayor peso (ver gráfica 1).

Gráfica 1. Producción de automóviles por países seleccionados, en miles de unidades, 1953-1990

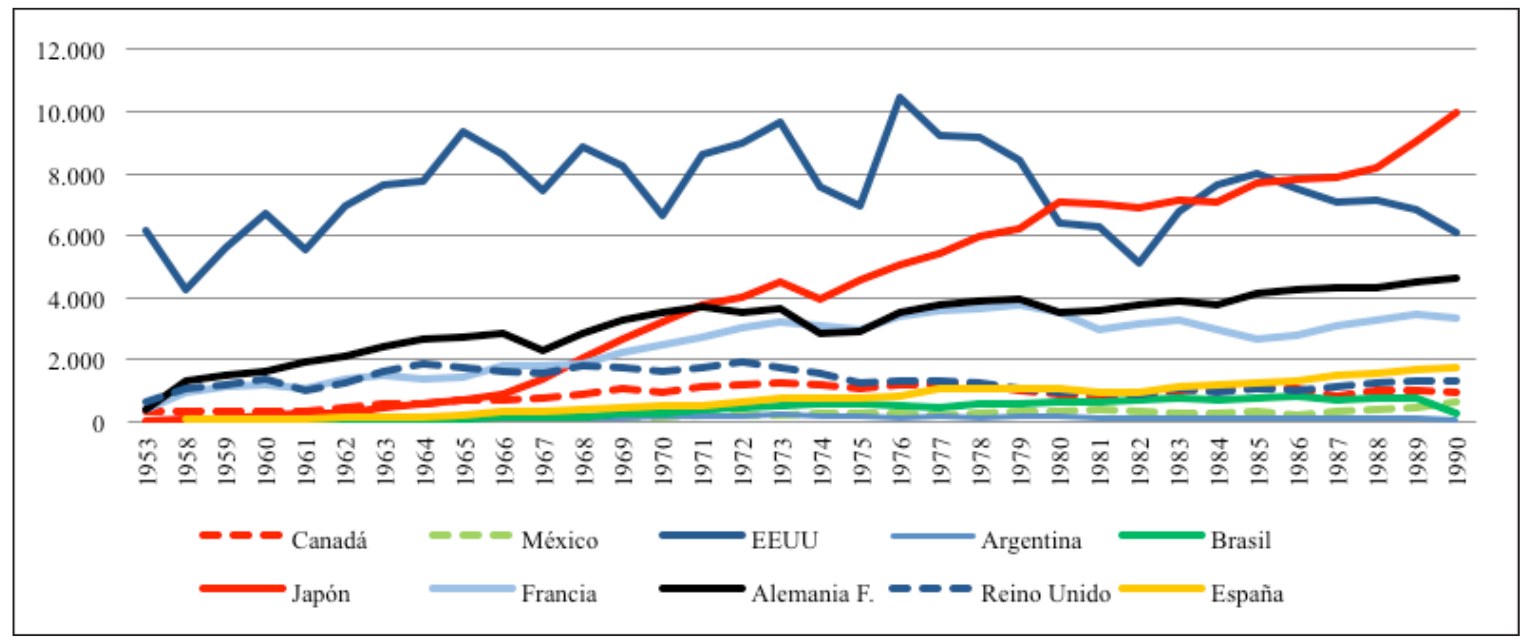

Fuente: elaboración propia con base en datos de Industrial Commodity Statistics Yearbook, ONU.

Japón, EE. UU., Francia, Inglaterra y Alemania dominaban la producción, concentrando entre un 75 y 90\%, según el año. Otros países, si bien expandían su complejo interno, no tenían peso internacional. Por ejemplo, para automóviles, Brasil sólo representó un 1,4\% de la producción mundial en el período, México, 0,9\%, y Argentina, 0,5\%. Estaba claro que estos países producían para sus propios mercados, sin capacidad de extenderse por el momento a otras regiones. En el caso de Argentina, esta pequeña escala fue un factor que dificultó la acumulación. En cuanto al comercio internacional, el panorama era similar, como muestra la gráfica 2. 
Gráfica 2. Exportación de automóviles de países seleccionados, en millones de dólares, 1962-1990

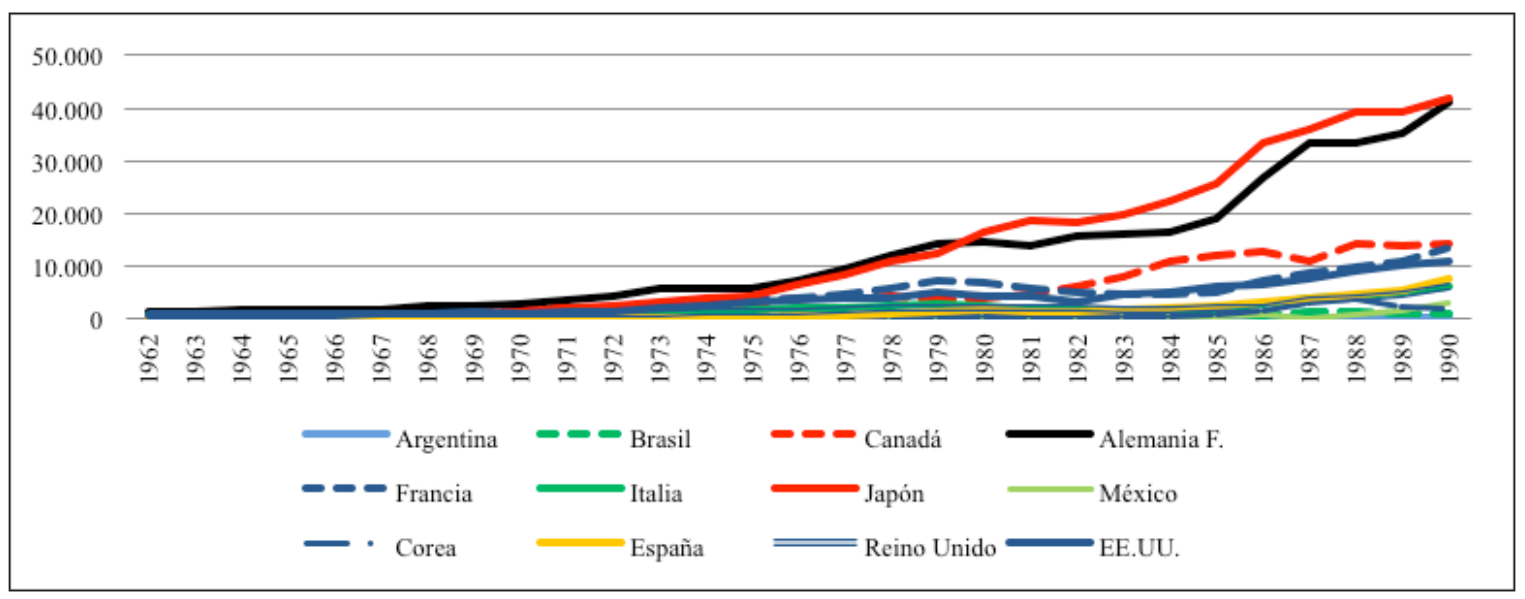

Fuente: elaboración propia con base en UN Comtrade.

El comercio mundial es dominado por los países tradicionales. Los niveles de producción y de exportaciones nos indican la escala de fabricación en cada país, y a su vez nos plantean la base para estudiar la industria de autopartes y otros suministros.

En autopartes, el panorama es el mismo (ver gráficas 3 y 4). Los países con el parque automotor más grande y con el mayor volumen de producción eran los que producían más partes de vehículos. Asimismo, eran los países que mantenían una mayor participación en el mercado mundial.

Gráfica 3. Participación en exportación de carrocerías de países seleccionados, en porcentaje del valor exportado, 1962-1990

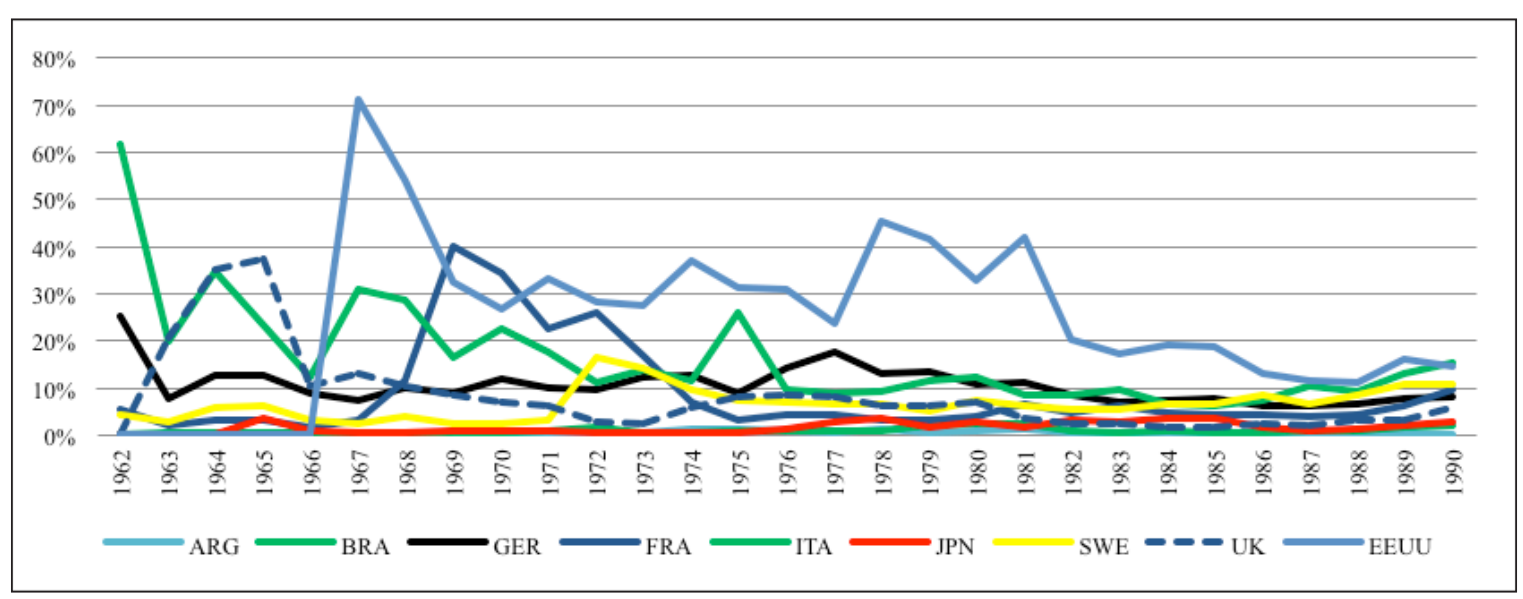

Fuente: elaboración propia con base en UN Comtrade. 
Gráfica 4. Participación en exportación de otras partes de vehículos por países seleccionados, en porcentaje de valor total exportado, 1962-1990

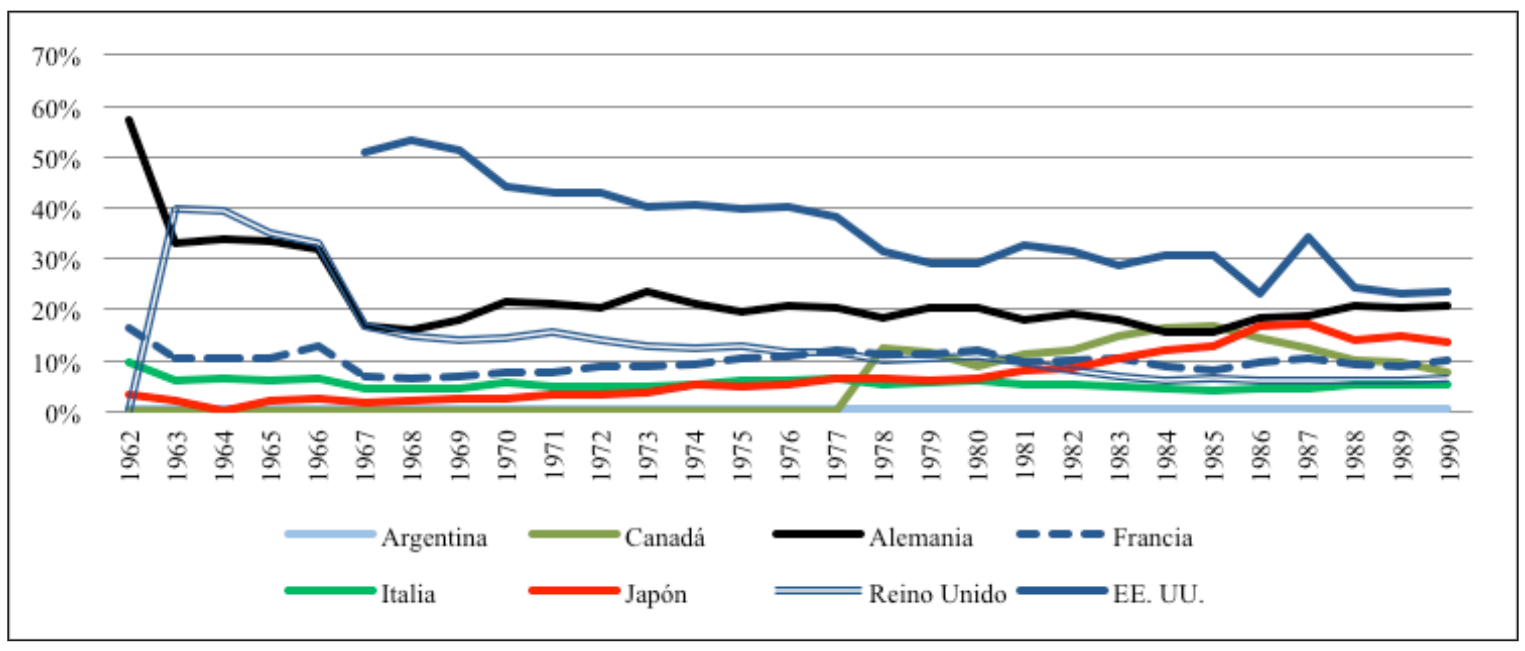

Fuente: elaboración propia con base en UN Comtrade.

Se reiteraba lo mismo que sucedía en el caso de la industria terminal. Los mayores productores, quienes contaban con una escala superior y marcaban la competitividad media, eran los que acaparaban las exportaciones internacionales. Es decir, los países que contaban con un sector automotor competitivo en el ámbito internacional.

\section{El caso argentino durante el período del mercado protegido. La situación del mercado interno}

En Argentina, luego de la crisis de los años treinta, comenzó a perfilarse un sistema de protección de hecho. Para los años cincuenta esta protección consistía en aranceles y su combinación con el tipo de cambio (protección efectiva), subsidios, exenciones impositivas, entre otros. La protección efectiva se encontró para el período estudiado por encima del $20 \%$ al nivel general (Iñigo Carrera, 2007; Kornblihtt, 2011). Por otro lado, existieron regímenes especiales para ciertos rubros. Para la metalmecánica, en la cual se encuentra la actividad estudiada, un estudio de los años setenta mencionaba:

[...] Los sectores productores de bienes de capital son los más protegidos, Vehículos y Maquinarias, tienen una protección de 242,6\% [...] los sectores, Automotores y Tractores y Maquinarias y Aparatos Eléctricos que se han clasificado en el caso 2. Las ramas incluidas en el caso 2 necesitan de la protección, ya que en un sistema de libre comercio no podrían subsistir. (Wainer, 1970, p. 24. El subrayado es nuestro)

Esto ocasionó un encarecimiento de las mercancías internas en relación con el mercado mundial, sobre todo en los insumos para la industria. Si bien permitió la acumulación en diversas ramas, provocará dificultades en la competitividad local. Para el caso de autopartes, 
estos aranceles superaron el $100 \%$ del precio CIF durante gran parte del período estudiado (ver Guía práctica del exportador e importador, varios años). ${ }^{1}$

Otra forma de protección fue la transferencia desde el Estado mediante subsidios, exenciones, créditos baratos. Así, el capital que se acumulaba en Argentina logró sobrevivir. Más aún, la tasa de ganancia del capital industrial, gracias a todas estas transferencias, alcanzó un nivel similar a la de EE. UU. (Iñigo Carrera, 2007). La posibilidad de compensar su menor competitividad industrial se debió a los ingresos por la vía de la renta diferencial agraria. Las exportaciones agrarias, portadoras de renta, permitían un ingreso extraordinario que el Estado apropiaba por diversos mecanismos y lo reasignaba de la forma mencionada, compensando la menor productividad. Eso también permitía pagar las mercancías más caras en el mercado interno, efecto del proteccionismo. Por otro lado, en este mismo elemento se encuentran sus límites, dado que la capacidad del Estado para llevar a cabo las transferencias estaba ligada a los vaivenes de la rama agraria y a los ingresos por renta diferencial. La crisis de fines de los setenta y comienzos de los ochenta provocó el desmantelamiento de este sistema de subsidios a los capitales más ineficientes, lo que afectó particularmente a la actividad. Las importaciones aumentaron, sobre todo en autopartes, y algunas terminales se retiraron del mercado. Hacia mediados de los ochenta, la salida de la crisis generó un mayor grado de concentración, y algunos autopartistas con cierta escala y tecnología sobrevivieron.

\section{El complejo durante la segunda mitad del siglo XX}

Nos basamos en los aportes de otros investigadores, principalmente en la tesis de doctorado de lanina Harari (2011), y en clásicos como Sourrouille (1980) y Baranson (1971), entre otros.

La fabricación íntegra propiamente dicha se inició luego de la Segunda Guerra Mundial. El inicio de la actividad tiene su origen en varios factores: cierre de las importaciones por el enfrentamiento bélico, envejecimiento del parque y crisis de divisas en el período 1949-52, factores principales que provocaron que en 1951 la industria fuera incorporada al régimen de protección y promoción. Dos años después, la sanción de la Ley de Inversiones Extranjeras permitió que se instalaran o firmaran acuerdos con capital local. Así, llegó IKA, y luego, Mercedes Benz, Ford, Citröen, Siam, y otros.

La primera experiencia de fabricación local en este período fue la de IAME. Su actividad fomentó el desarrollo de autopartistas en el cordón Córdoba-Santa Fe y Buenos Aires, al encargar piezas a estos proveedores y financiarlos por diversos medios. No obstante, los límites de esta industria dificultaron la producción e impidieron el aumento de la escala. En cuanto a los capitales privados que se instalaron, en ese primer momento establecieron plantas con una escala reducida, en comparación con los parámetros mundiales. En el caso de IKA, intentó proveerse de partes con la compra de talleres y la instalación de establecimientos para fabri-

1 En futuros trabajos, sistematizaremos la estadística de aranceles para el sector automotor y de autopartes, con el fin de mensurar el nivel de protección efectiva (transferencias) con el que contó la actividad durante estos años. 
cación de piezas. Pero el costo de las partes nacionales fue muy elevado. Al ser una empresa con un alto nivel de integración, IKA sufrió ese factor, lo que perjudicó su competitividad, aun en el mercado local.

En marzo de 1959 se firmó el decreto 3693, conocido como Régimen de Promoción de la Industria Automotriz. El decreto brindaba una serie de beneficios para las firmas. Por un lado, se elevarían aranceles a terminados; además, plantas que utilizaran partes nacionales recibirían ventajas cambiarias y arancelarias, y se les garantizaba la provisión de divisas. Entre 1959-60 se aprobaron planes para la instalación de 23 firmas, aunque hacia 1964 once firmas habían abandonado la producción.

Este sector continuó siendo deficitario en su balanza. En un estudio de los setenta, Remes Lenicov indicaba la forma en que se dio la instalación de la industria:

La eficiencia es un aspecto que en los hechos y por el procedimiento llevado a cabo no se tuvo en cuenta; y por esta causa tenemos un sector industrial con altos costos que perjudica tanto a los usuarios, como así también impide la ampliación del mercado interno y sobre todo el externo, donde es imposible sostener una política agresiva y con posibilidades de éxito y continuidad en materia de exportaciones. En EE. UU., una planta para que sea óptima debe producir 600.000 unidades anuales, siendo los costos moderadamente más altos para plantas de 150.000 unidades y considerablemente mayores para aquellas de 60.000 unidades anuales; mientras que las que producen menos de esta última cantidad son despreciadas por su alto grado de ineficiencia. (Remes Lenicov, 1974, pp. 122-123)

No se logró atenuar el déficit comercial, uno de los objetivos con los cuales se había fomentado la actividad. Atendiendo a ese problema, bajo la administración de Arturo Illia se intentó aumentar la obligatoriedad de la integración nacional. Se pretendía llegar a un 96\% en 1968 (Sourrouille, 1980, p. 57). Para ello, algunas firmas establecieron secciones especiales. Otras, como Siam Di Tella, directamente compraban paquetes de empresas autopartistas. Pero en general, se optaba por tercerizar la producción de autopiezas comprando a proveedores, entre ellos IKA (luego Renault), que era la firma más integrada y proveía de piezas a otras terminales.

Un problema relativo a la organización productiva era el de las matrices. Las que se importaban de EE. UU. o Europa no siempre eran adecuadas para la fabricación local, por lo que debían adaptarse. Eso obligaba a tareas de adaptación, que incrementaban el tiempo de producción de las piezas y, por ende, su costo. En el famoso informe de Jack Baranson para el Banco Mundial se aseguraba que "en las prensas de estampación de las carrocerías hay que cambiar varias veces las pesadas matrices para ir fabricando en pequeñas series los 20 o 30 paneles de chapa que lleva cada modelo de coche o camión" (Baranson, 1971, p. 60). Esto significaba un encarecimiento de los precios de venta:

[...] el consumidor argentino estaba pagando 2,2 veces el precio de un automóvil equivalente a los precios internacionales; según el informe, a un valor unitario promedio internacional de un vehículo comparable, debían agregarse 55 puntos por deseconomías de escala, 13 puntos por factores vinculados al manejo técnico- 
empresarial de las fábricas terminales, 30 a cuestiones equivalentes que atañen a las proveedoras y 22 a lo que se dio en llamar factores exógenos. (Sourrouille, 1980, p. $63)^{2}$

La cámara de las firmas terminales tenía una evaluación similar del problema. Según ADEFA, a partir de un estudio propio,

Efectuando una media ponderada basada en el porcentaje que le corresponde a cada especialidad en la apertura del precio del automotor, se llega a que las partes son aproximadamente un $101 \%$ más caras que en los países originarios de las marcas de automotores que se fabrican en el país. (Adefa, 1969, p. 51)

Varios estudios del período ilustraron este diferencial de costos que afectaba la producción local. La raíz del problema se encontraba en la siderurgia, que luego extendía esos déficits al resto de la producción encadenada (ver gráficas $5 a, 5 b$ y 6 ).

Gráficas $5 a$ y $5 b$. Porcentaje (por encima) de precios de insumos siderúrgicos argentinos en relación con similares del mercado europeo, 1964; y mayor porcentaje de precios con respecto al internacional de algunos insumos en la industria de autopartes argentina, 1968

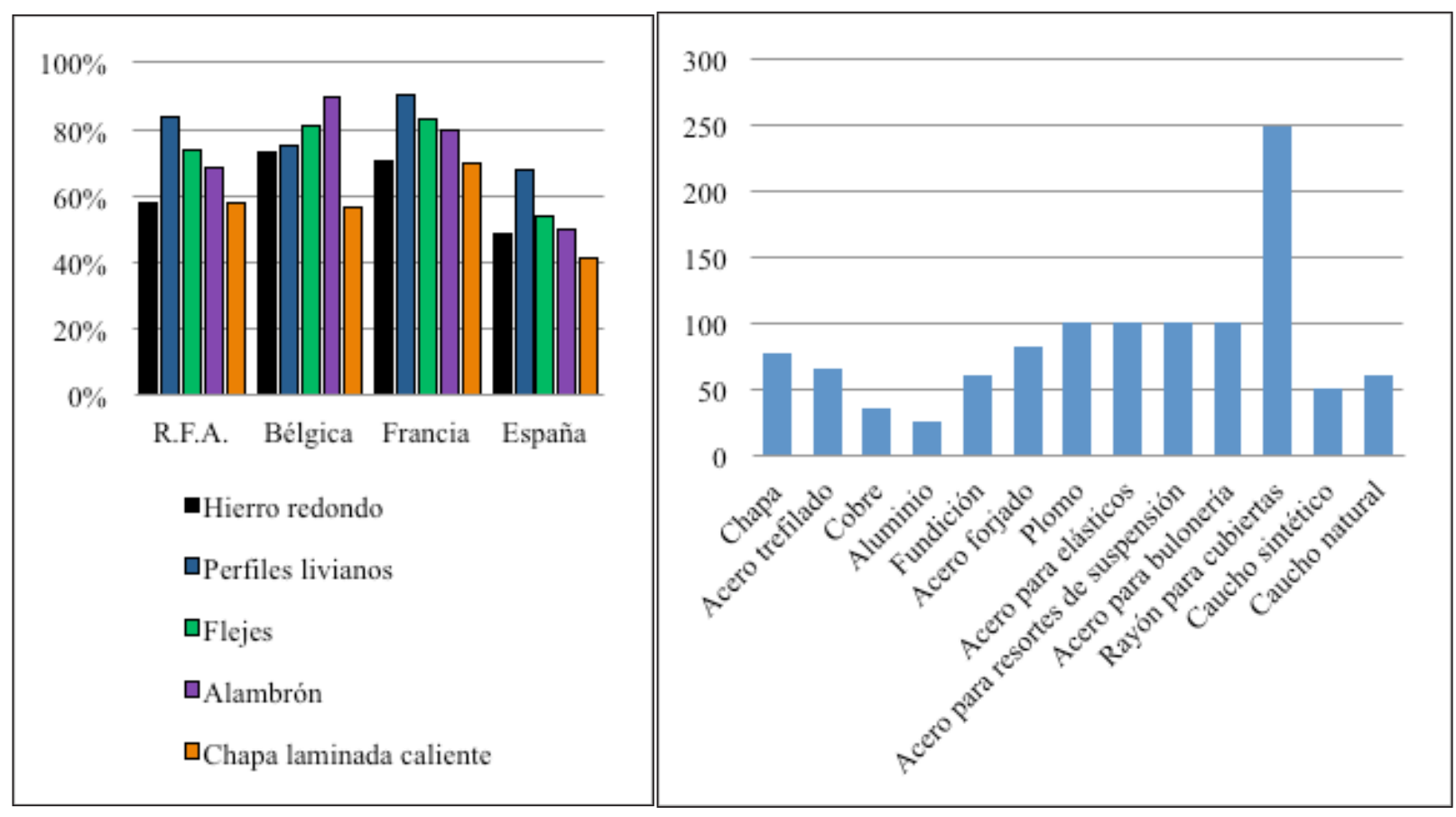

Fuente: elaboración propia con base en Conade (1966, p. 107) y Adefa (1969).

2 Lo mismo decía Jack Baranson: en 1967, los costos de producción en Argentina eran 2,5 veces mayores que los de un vehículo equivalente importado de Europa o EE. UU. 
Gráfica 6. Diferencia de precio de pieza nacional seleccionada vs. homóloga importada de EE. UU. (referida en dólares), industria automotriz, 1965

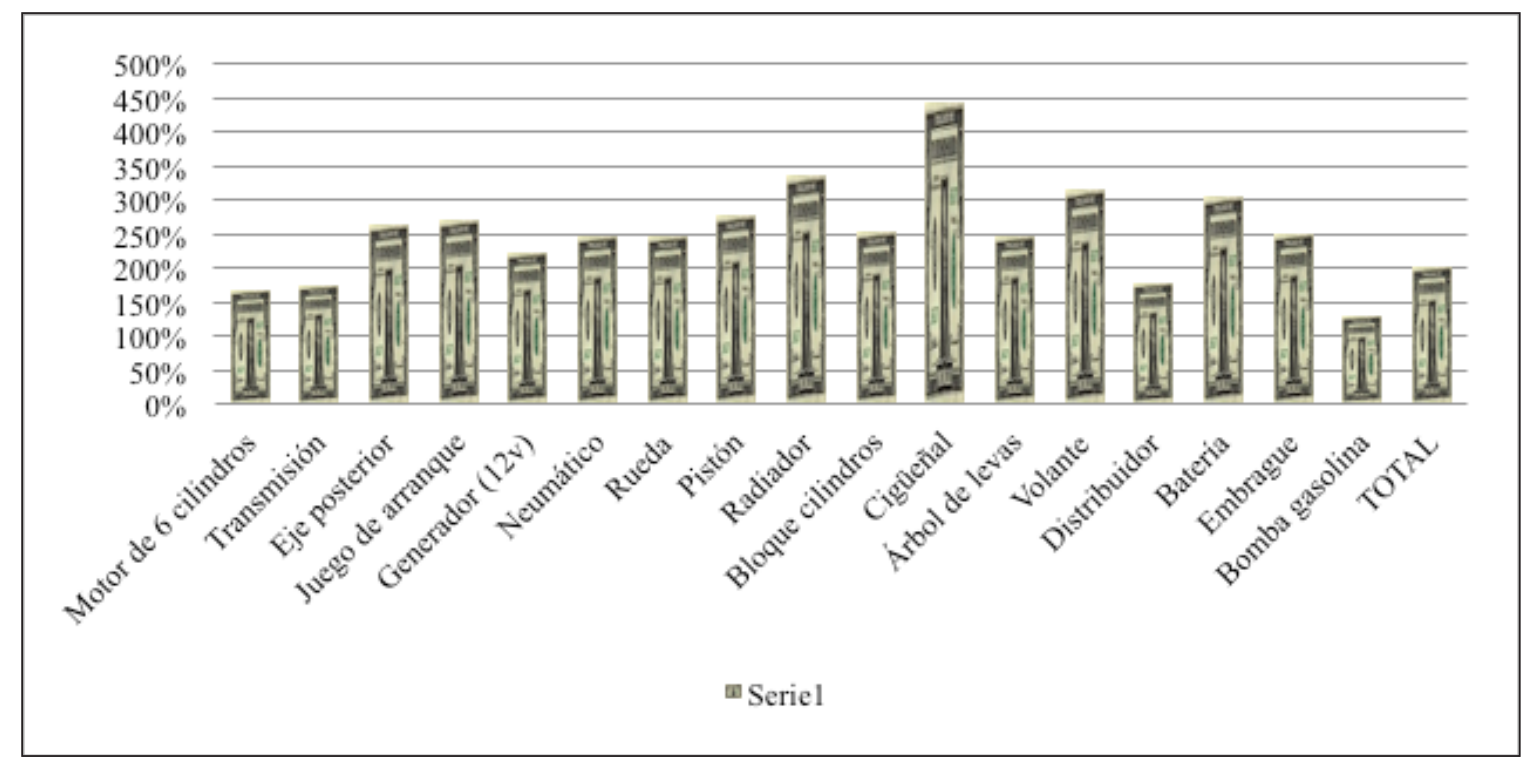

Fuente: elaboración propia con base en Baranson (1971).

Estas diferencias repercutían en el costo de producción de la terminal. Los costos en Argentina superaban en dos o más veces a los de la producción automotriz norteamericana (ver gráfica 7), una de las referencias internacionales. Por eso, la producción local precisaba la protección estatal.

Gráfica 7. Costo de producción de Jeep y Rambler en Argentina y EE. UU., 1965

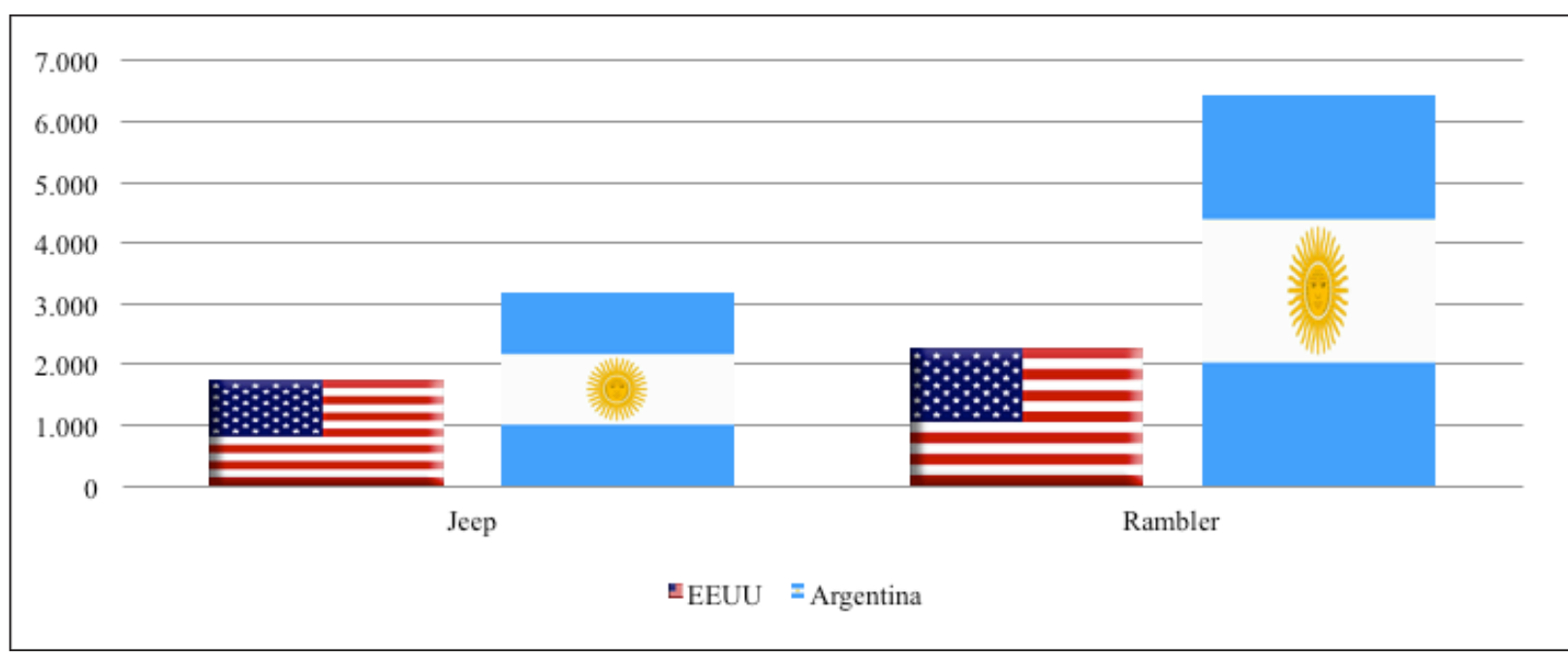

Fuente: elaboración propia con base en Baranson (1971).

tiempo\&economía

$\mathrm{N}^{\circ} 2$ - I semestre de 2015 
En lo que respecta a la industria autopartista fuera de planta, en los sesenta y setenta el sector se modernizó con el ingreso de filiales de firmas extranjeras. También se dio un proceso de concentración. El crecimiento fue "segmentado": las grandes firmas se dedicaron a proveer a las terminales, mientras que los pequeños autopartistas quedaron relegados al mercado de reposición (Barbero y Motta, 2007). Para 1973, los pequeños generaban sólo el 8\% de la producción.

La industria autopartista se expandió, en buena medida, gracias al régimen de promoción que imponía la obligación de integración nacional. Las terminales que no cumplían con esto debían pagar un recargo del 200\%. En 1964, la integración exigida era de $90 \%$ para autos y $80 \%$ para camiones. Esto, beneficioso para las autopartistas, afectaba a las terminales, debido a las deficiencias de los proveedores. Por eso, varias armadoras instalaron plantas para producir piezas. El esquema de protección a autopartes buscaba reducir las importaciones y la utilización de divisas del sector. En 1971 se da una disputa frente a la renovación de este esquema legal, por el costo de las unidades (Harari, 2010). Ambos contendientes reconocían que el complejo tenía altos costos, debido a las deficiencias en el abastecimiento de materias primas, que se trasladaban al resto de la cadena. Por otra parte, el tamaño del mercado argentino afectaba a la industria autopartista, cuya escala también resultaba chica y, por lo tanto, limitaba la tecnología empleada. Asimismo, la calidad de los productos solía ser deficiente, como señalaba Baranson para el caso de material eléctrico, forjado, fundiciones, cromados, plásticos y vinílicos, además de las carrocerías, por falta de chapas acordes para este producto (Baranson, 1971, p. 60). A su vez, la baja productividad de las autopartistas implicaba que los precios de sus productos se encontraran incluso por encima del costo de los importados. En ese contexto, las terminales pugnaron para reducir el cupo de integración local. Pero la posición que primó fue la de las autopartes: el Régimen de Reconversión de ese año acepta ciertas reivindicaciones de las terminales, como la prohibición de importación de vehículos hasta 1980, pero en su conjunto benefició a los autopartistas. Estos obtuvieron el sistema de "listas positivas", donde el recargo para importación de partes se establece según la disponibilidad de cada pieza en el mercado local; además, se fijaron topes de entre 5 y 10\% de importación para autos y camiones (una leve reducción de la situación previa), y un reintegro de 50\% para los que exportaran.

Volviendo a lo que es el complejo en su conjunto, estas décadas constituyeron un período de concentración. Ello derivó en un aumento de la productividad. Para 1970, sólo quedaban diez terminales, pero la producción había aumentado más del doble en relación con 1960. A pesar de esta circunstancia, la escala en Argentina no logró alcanzar la de los países líderes. Al respecto, Baranson mencionaba que en las "fábricas destinadas a servir a un mercado interior limitado, estas técnicas más eficientes (mecanización y automatización) están descartadas de antemano, en razón precisamente del escaso volumen del mercado" (Baranson, 1971, p. 34). En ese sentido, se calculaba en esas décadas que el volumen mínimo de producción para poner en funcionamiento una línea automotriz, con ensamblado y producción de motores, como sucedía en el caso argentino, era de 250 mil unidades anuales con la tecnología más avanzada. En el caso de las plantas que sólo se dedicaban al ensamblado, sin la elaboración de ninguna autoparte, el piso se reducía a 120 mil unidades. Por añadidura, la escala debía aumentar si se incorporaba la producción de piezas, debido a que estos procesos se encontraban más mecanizados que el ensamble (donde se utilizaba menos número de máquinas herramientas). En 
aquellas secciones donde la inversión en maquinaria era mayor, también lo era la escala necesaria para amortizarla. Por otro lado, el límite del mercado interno provocaba que las empresas operaran con capacidad ociosa (alrededor del 40\%), por lo cual traer equipos con mayor capacidad productiva hubiera sido antieconómico para ellas.

En Argentina, donde las plantas fabricaban motores, el volumen total de la producción de todas las firmas establecidas no llegaba al mínimo de 250.000. Esta cifra sólo se alcanzó, y se superó levemente, entre 1972 y 1974, luego de los cuales sobrevino la crisis del sector. Como ejemplo, en 1965, mientras que en Estados Unidos se produjeron 11.112.000 de vehículos, en Argentina se fabricaron sólo 196.800 (gráfica 8). La escala de mercado también ilustra esta situación.

Gráfica 8. Ventas o licenciamientos en países y años seleccionados, 1970-1995

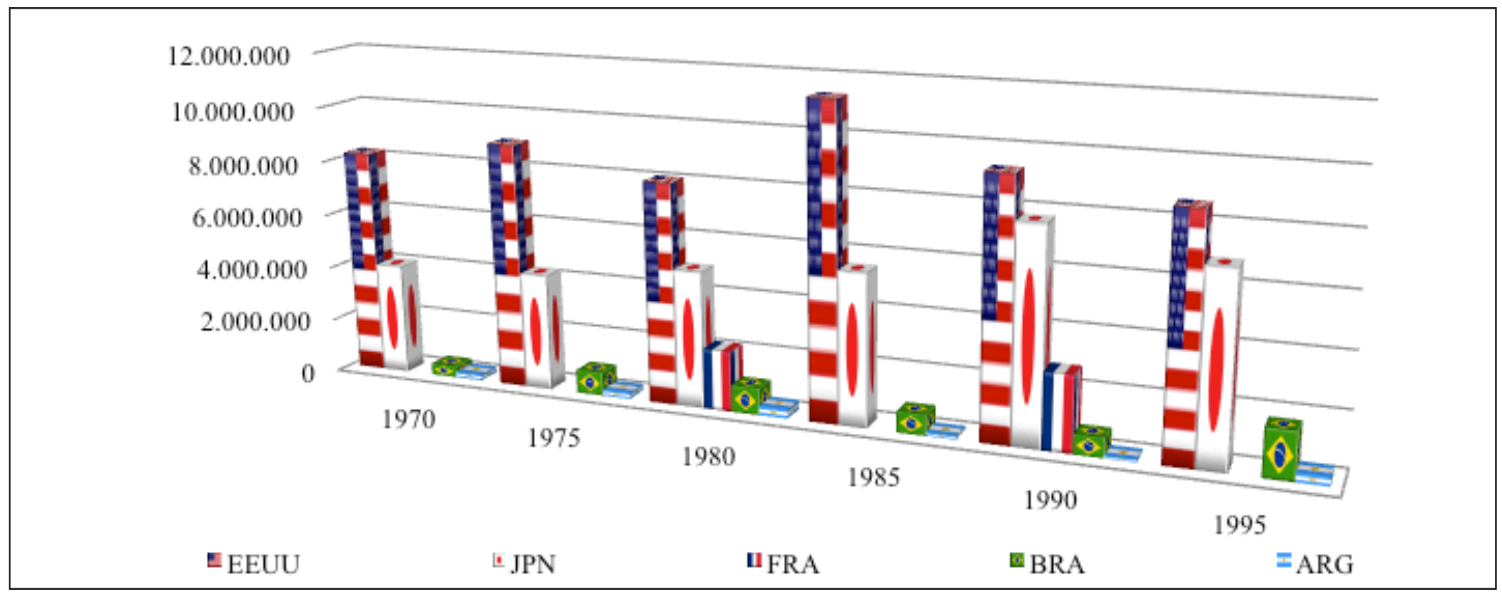

Nota: para EE. UU. sólo se contabilizan automóviles (para el resto, vehículos totales)

Fuente: basada en datos de Barbero y Motta (2007), Anfavea (2008), U.S. Statistical Abstracts, Anuarios de las Cámaras Francesas (CCFA, 2012) y Japonesas (Jama, 2012) de fabricantes de automóviles.

La escala planteaba un límite para la producción local de automóviles y de autopiezas. Además, la crisis de 1978-79 repercutió sobre la situación financiera. En Argentina llevó a varias empresas a la quiebra o a retirarse del mercado. Ante la imposibilidad de sostener el marco de incentivos a la industria, se relajaron las restricciones a la importación, lo que permitió el ingreso de unidades y piezas. A pesar de que las importaciones se estabilizan en 1982, la industria no recuperó el rezago en relación con la media mundial. En cuanto a la actividad de autopartes, la crisis presionó la concentración del sector. Un estudio de comienzos de los ochenta señalaba que un $80 \%$ de las compras de terminales en Argentina se hacían a los 250 proveedores más grandes (Lifschitz, 1982). Cincuenta empresas cubrían un 75\% del mercado y 15 alcanzaban a sumar 50\% de compras (Salerno et al., 1989, p. 54).

En 1986 comenzaron los acuerdos de integración con Brasil, comoantesala de la conformación del mercado común y de cambios más generales en la industria en el ámbito internacional. Según Barbero y Motta, las empresas de ambos países vieron en la complementación una vía para superar las restricciones de escala de ambos mercados, aunque el comercio no alcanzó los valores de mediados-fines de los setenta. 


\section{Las importaciones del sector automotor argentino: volumen y origen}

Si bien durante el período analizado las importaciones se contrajeron por el proteccionismo, no se redujeron a cero. Continuaron ingresando vehículos, cuyos modelos no se fabricaban en el país, y, sobre todo, piezas diversas. Entre la segunda mitad de los cincuenta y comienzos de los sesenta, contamos con información para diferentes conjuntos (ver la gráfica 9).

Gráfica 9. Importación argentina de autopartes por rubro, en dólares, 1955-1962

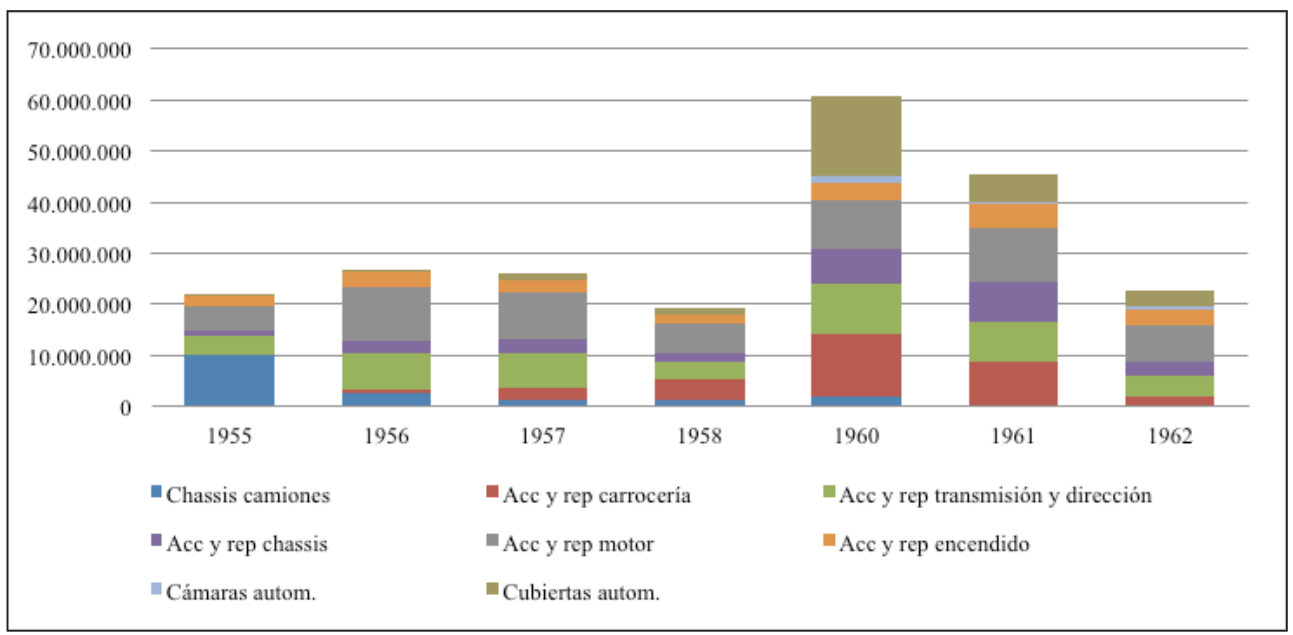

Fuente: elaboración propia con base en Anuario de Comercio Exterior. ${ }^{3}$

Los valores de importación durante la siguiente etapa, a partir de comienzos de los sesenta, aparecen en las gráficas 10 y 11 .

A pesar de la política de protección para el sector, la importación existió. Incluso, durante los años en que los ingresos parecen ser reducidos, las importaciones generaban déficit de la balanza. Motores y partes, los rubros de mayor peso, inician un ciclo ascendente de importación a mediados de los sesenta que no se detendrá en su tendencia, a pesar de algunas breves interrupciones, como en 1978 o en 1982-83 (ver gráfica 12).

Como tendencia histórica, el sector mantuvo un déficit crónico, salvo algunos pocos años en los setenta. La industria terminal tuvo ciertos momentos de esplendor, en los que su saldo fue superavitario, pero en términos del complejo, se sostuvo el déficit. Esto fue producto del saldo negativo de la balanza de autopartes, sector que, a pesar de todas las medidas de protección y estímulo, no logró revertir sus inconvenientes en costos y proceso productivo. Este factor - determinado por la escala y por los problemas de la siderurgia argentina - es el que se encuentra detrás de los límites de la actividad en este período.

3 El universo de autopartes abarca un gran número de piezas y conjuntos que no siempre se encuentran desagregados en las estadísticas públicas. Para este trabajo, agrupamos las mercancías del sector en las categorías que se informan en las fuentes consultadas (Anuario de Comercio Exterior de Argentina y la base UN Comtrade). Queda pendiente para futuros trabajos una desagregación mayor del universo autopartista. Para ello, un buen punto de partida es la clasificación que elaboraron Ana Garriz y Hernán Soltz, que se detalla en la segunda parte de este artículo. 
Gráficas 10 y 11. Importación de partes y conjuntos y de otra partes de vehículos por Argentina, en dólares corrientes, 1962-1990

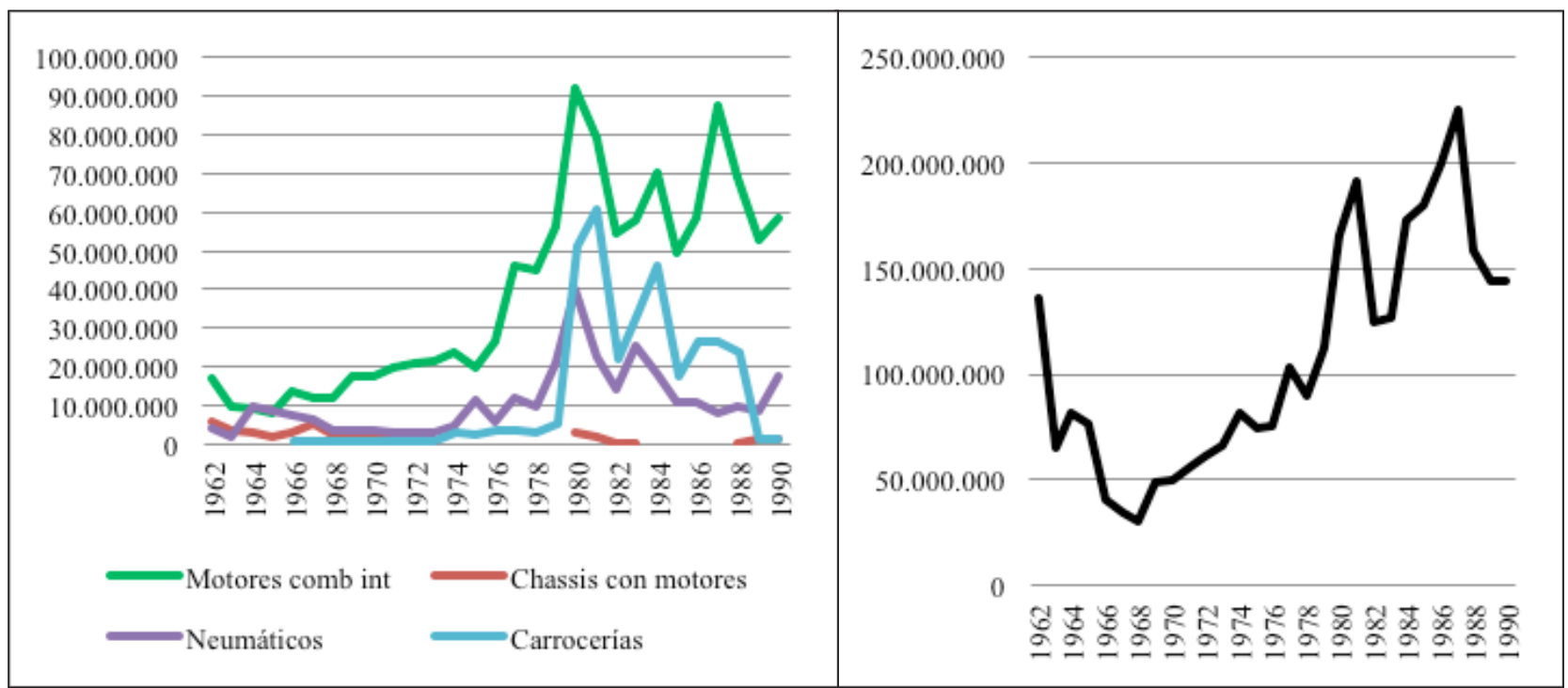

Fuente: elaboración propia con base en UN Comtrade.

Gráfica 12. Importaciones y exportaciones del complejo automotor argentino y saldo comercial de la actividad, en millones de dólares corrientes, 1962-1990

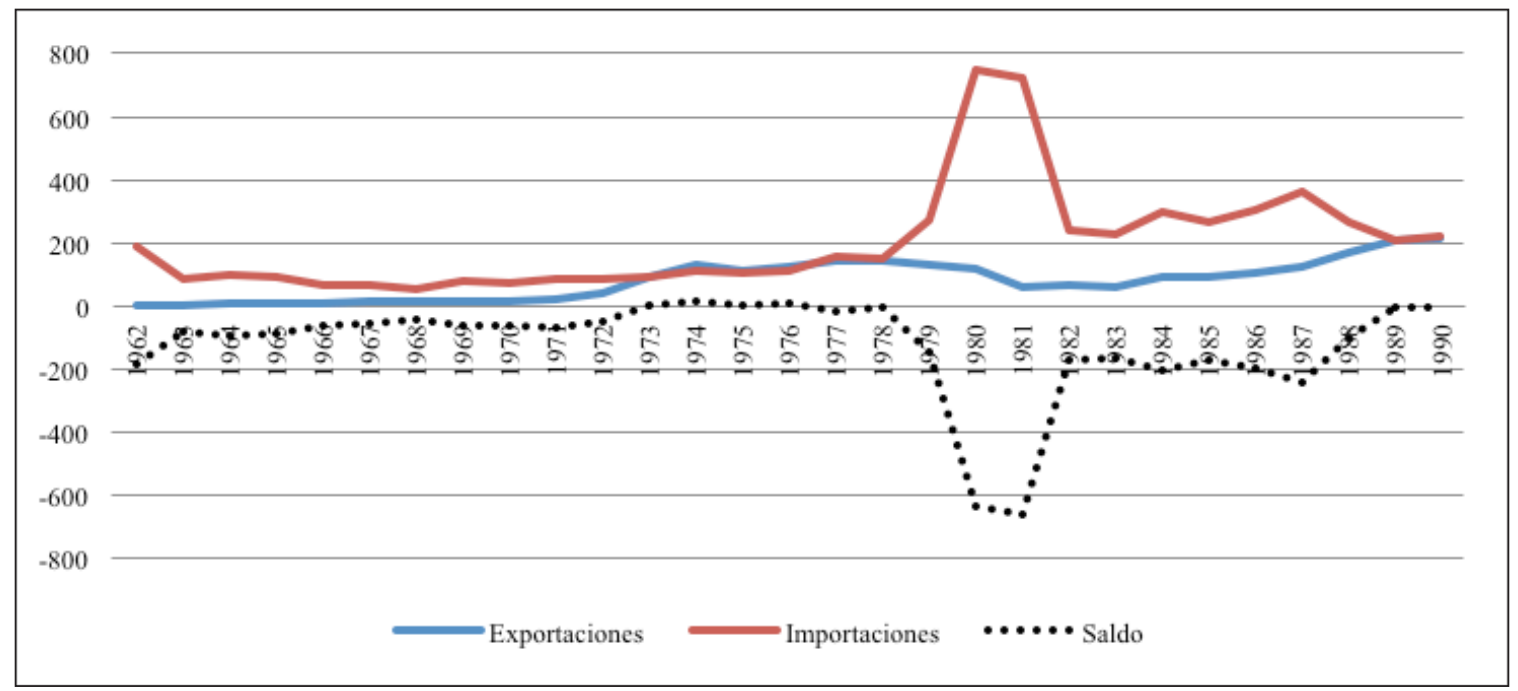

Fuente: elaboración propia con base en datos de UN Comtrade (varios años) (incluye autos, comerciales y camiones, y los datos de las gráficas 11 y 12, excepto neumáticos). 


\section{La actividad luego de la conformación del Mercosur}

\section{Los condicionantes generales de la actividad y la balanza 1993-2012}

Durante los ochenta, como sucedió en el ámbito mundial, el sector automotor en Argentina experimentó una crisis. Recién a partir de la conformación del Mercosur, la actividad en la región se recuperó en sus indicadores. Esto se debió al incremento de la escala y a la reestructuración de un sistema de subsidios y beneficios para las terminales. En el caso argentino, durante los años noventa la sobrevaluación de la moneda volvió a ofrecer beneficios para los capitales extranjeros. Ello provocó el retorno al país de varias multinacionales que habían abandonado Argentina, o bien habían vendido su licencia (como Fiat o Peugeot, que cedieron la marca y tecnología al grupo local Sevel).

Durante la década posterior, las terminales se beneficiaron de la devaluación, que deprimió el salario y el costo laboral. Por otro lado, recibieron en forma de subsidios gran parte de la política pública. Estas políticas consistieron en medidas crediticias y de subsidios, tendientes a resguardar la rentabilidad de las terminales que operan en el país. Esto tuvo como consecuencia el alcanzar niveles récords de producción, que se ubicó en los últimos años cercana al millón de unidades; así como picos de ventas y facturación (ver gráficas 13, 14 y 15). Entre 2002 y 2011 , las tasas de crecimiento de la industria terminal alcanzaron un 22,1\% anual acumulativo (Manzanelli y Castells, 2013).

Durante la primera década de los años 2000, este panorama también provocó la afluencia de nuevos participantes que instalaron sus plantas, como Toyota y Honda. En Argentina, once terminales internacionales cuentan con plantas de producción, ${ }^{4}$ para un mercado catorce veces menor que el norteamericano y cuatro veces menor que el brasileño o mexicano, y que podría ser abastecido con la mitad de lo que fabrica una empresa coreana en su país.

Como se desprende de las gráficas, durante la última década la producción de vehículos alcanzó sus máximos históricos. Esta tendencia comienza luego de la conformación del Mercosur. En ese sentido, y dicho sea de paso, los valores de producción y exportación del sector durante los noventa ponen en duda, al menos para esta actividad, la existencia de la mentada "desindustrialización" que postula la gran mayoría de los autores que interpretan el sector.

No obstante, la aparente pujanza del complejo contiene una serie de elementos que ponen un límite al entusiasmo descripto. Indagando con mayor profundidad, se evidencia que poco cambió en la trama de la actividad, así como en la estructura industrial argentina.

Por un lado, la actividad precisa una serie de transferencias, que se expresan en los créditos a la actividad y, sobre todo, en la protección efectiva, y otros proyectos de financiamiento (como el Fondo del Bicentenario, o los subsidios del programa Repro). Un desarrollo mayor de este particular queda pendiente para futuros artículos (ver las gráficas 14 y 15).

4 Fiat, Ford, General Motors, Honda, Iveco, Mercedes Benz, PSA (Peugeot-Citröen), Renault, Scania, Toyota y Volkswagen. 
Gráfica 13. Producción, ventas y exportaciones de automóviles en Argentina, 1959-2011

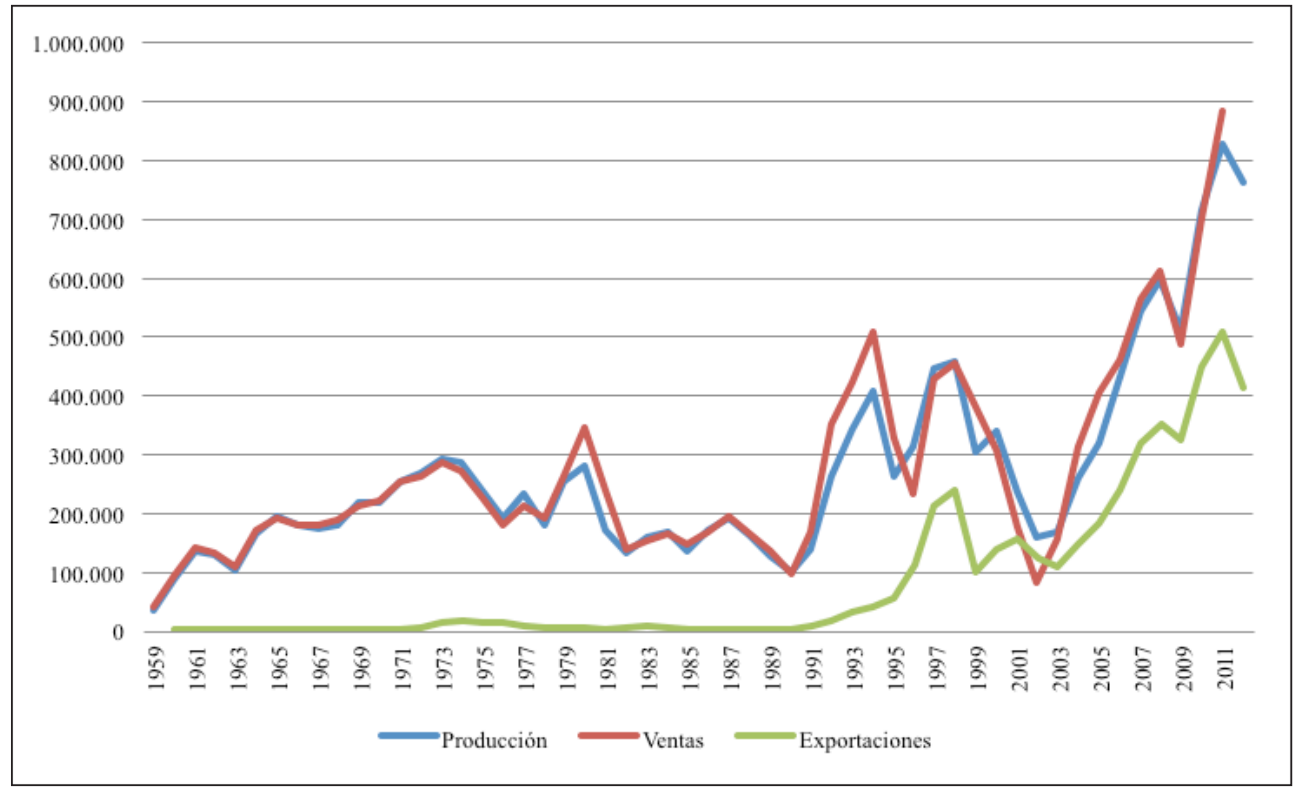

Fuente: elaboración propia con base en datos de Adefa (2013).

Gráficas 14 y 15. Participación del complejo automotor en la inversión total del sector industrial y créditos al complejo automotor (datos del cuarto trimestre de cada año),

participación en el total de créditos a la industria, 1995-2012

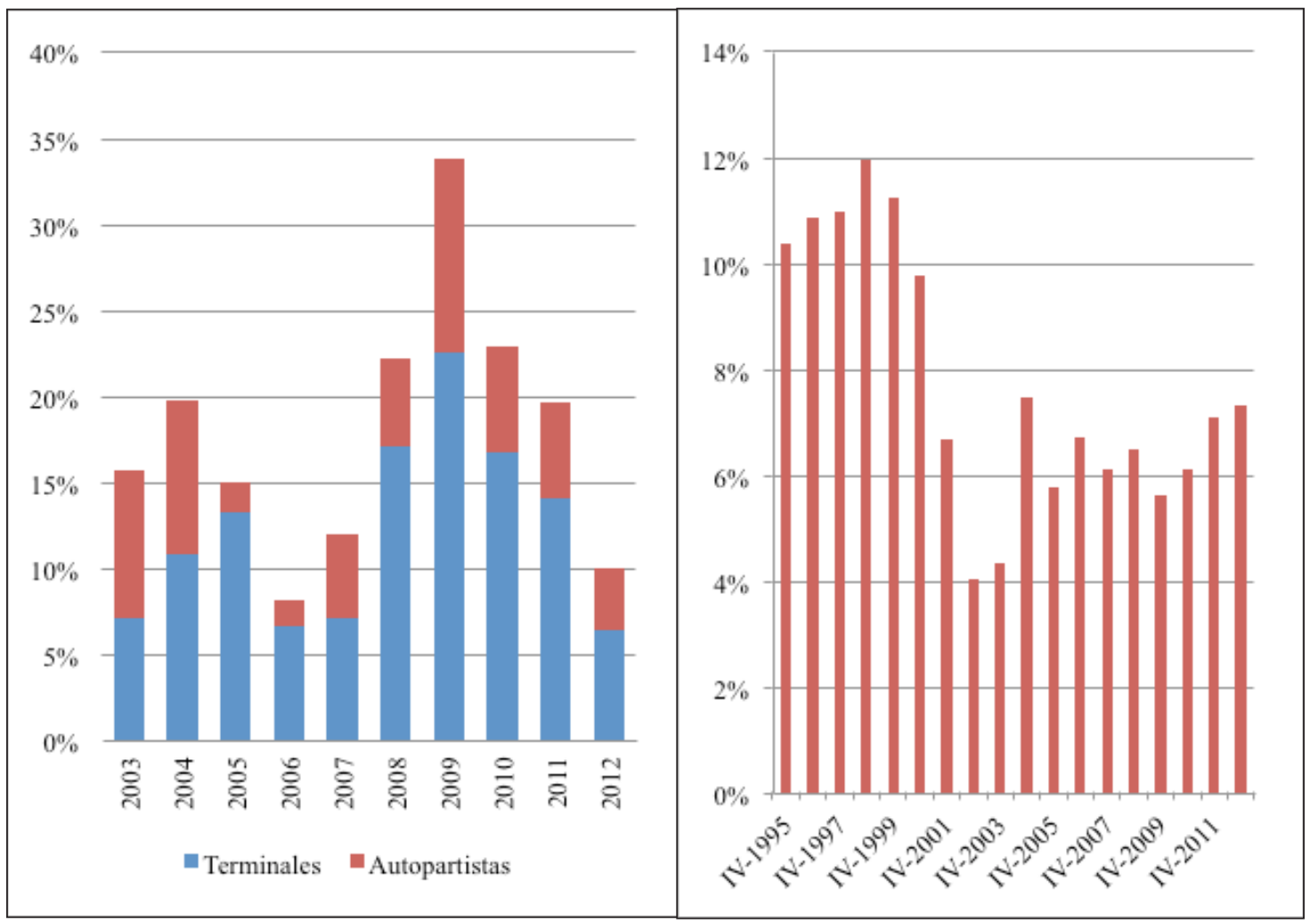

Fuente: elaboración propia con base en datos del CEP (2013).

tiempo\&economía

$N^{\circ} 2$ - I semestre de 2015 
El otro gran problema del complejo se evidencia en la debilidad de los encadenamientos: el autopartismo no logra revertir su tendencia deficitaria. Más aún, ante la menor eventualidad, entra en crisis mostrando sus problemas de competitividad. Al nivel agregado, el superávit creciente de las terminales es superado por el déficit, también creciente, de la industria de autopartes. Ello es indicio de que los antiguos problemas continúan vigentes. La situación del complejo desde esta perspectiva, a partir del comercio exterior argentino en la actividad, se aprecia en la gráfica 16.

Gráfica 16. Saldo comercial de autopartes, en millones de dólares corrientes, Argentina, 1993-20125

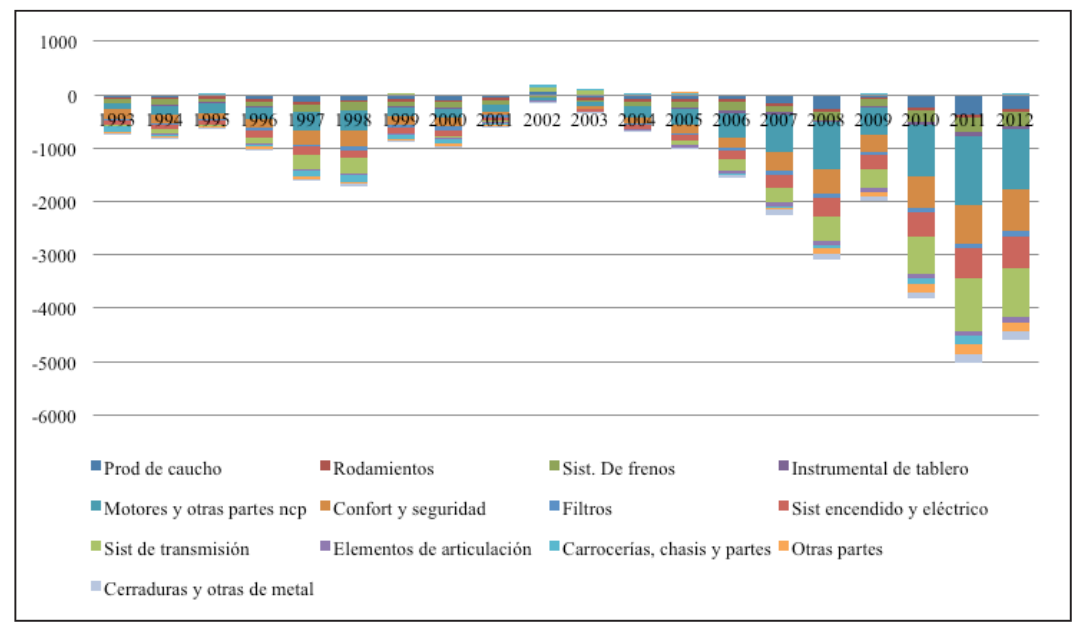

Fuente: elaboración propia con base en UN Comtrade.

El déficit por conjuntos es crónico, salvo en 2002, el peor año de la crisis, momento en el cual la retracción de la actividad provocó la caída de las importaciones. A diferencia de lo que sostienen algunos autores, la balanza comercial no muestra sectores o "nichos" que resulten ser potencialmente una opción exportadora o de inserción internacional. Incluso, las pocas actividades superavitarias durante ciertos años de la última década, como partes de encendido eléctrico, limpiaparabrisas o transmisiones, durante los últimos años volvieron a registrar déficit en sus respectivas balanzas. La única partida superavitaria es la de carrocerías. No obstante, casi el 70\% de ese comercio se realiza con Brasil. Por otro lado, Argentina tiene una participación menor en el mercado mundial en ese rubro: apenas un 0,45\% de la exportación mundial.

Entonces, se importa, y cada vez más. En ese sentido, lo llamativo es que, a medida que se incrementa la producción de vehículos terminados y se agranda el negocio de las terminales, se hace más deficitaria la balanza de autopartes y de todo el complejo. Es decir, a medida que

5 Para la construcción de esta gráfica utilizamos las siguientes partidas arancelarias de la base UN Comtrade: 401110, 401120, 401310, 401693, 409120, 681310, 681381, 681389, 700711, 700721, 700910, 701400, 731816, $830120,830210,830230,840734,840790,840820,840991,840999,841330,841520,842123,848310,848320$, $848330,848340,848350,848360,848390,850710,851110,851120,851130,851140,851150,851180,851190$, $851240,851320,852721,852729,854430,870500,870600,870810,870821,870829,870830,870831,870839$, $870840,870850,870860,870870,870880,870891,870892,870893,870894,870895,870899,902910,902920$, 902990, 910400, 940120. 
aumenta la producción automotriz, queda en evidencia el déficit de los encadenamientos productivos en el país (ver gráfica 17).

Gráfica 17. Contenido de valor importado de un vehículo fabricado en Argentina, 1993-2012

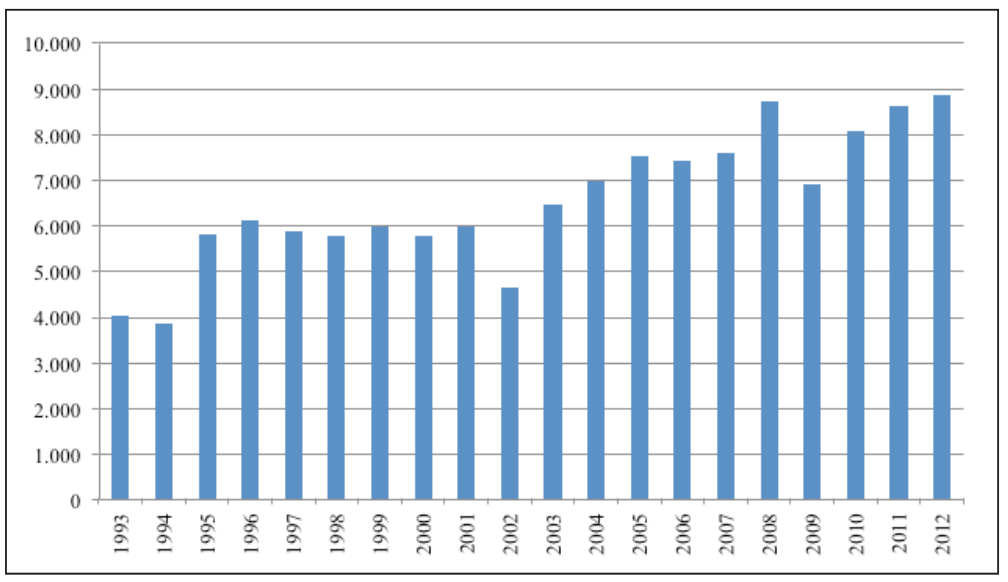

Fuente: elaboración propia con base en datos de UN Comtrade y Adefa.

Un vehículo de producción argentina cuenta, en su costo, con casi 9.000 dólares de insumos importados, en el último año principalmente de Brasil, seguido de Alemania, China, EE. UU. y Japón. Cabe aclarar que éste es un cálculo conservador, ya que otros autores calculan más de 12.000 dólares de composición importada por vehículo (Llach, 2011). Según cálculos de Ana Garriz y Hernán Soltz, la composición de importados por vehículo para 2011 era de 10.028 dólares por vehículo, mientras que en China, Japón y Corea del Sur la misma variable no superaba los 2.700 dólares (Garriz y Soltz, 2013). En consecuencia, el déficit del saldo comercial del complejo se profundiza, como se ve en la gráfica 18.

Gráfica 18. Saldo comercial del complejo automotor argentino (terminales y autopartes), en millones de dólares, 1993-2012

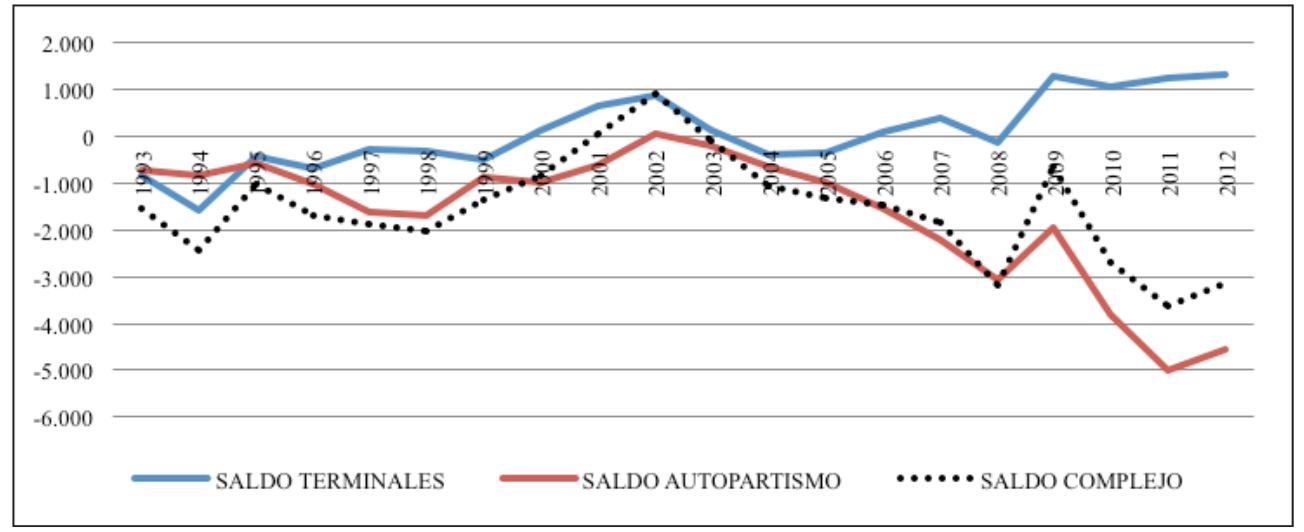

Fuente: elaboración propia con base en datos de UN Comtrade.

tiempo\&economía

$\mathrm{N}^{\circ} 2$ - I semestre de 2015 
La gráfica evidencia que el complejo automotor argentino mantiene su característica histórica en cuanto al saldo de su balanza comercial. Desde 1993 hasta la actualidad, salvo en 2002, la actividad mantuvo un déficit constante. Es interesante que desde fines de los noventa, las terminales comienzan a tener un saldo exportador positivo. Pero ello tiene como contrapartida la profundización del déficit de autopartes. El resultado es el crecimiento del déficit comercial argentino. En este punto, es interesante la relación con Brasil. El país vecino mantiene una balanza deficitaria de la actividad desde 2008, y en 2012 alcanzó los 15.000 millones de dólares. No obstante, con Argentina tiene saldo positivo, sobre todo por la provisión de autopartes. En efecto, como mencionamos previamente, los principales proveedores de Argentina que explican su déficit comercial desde 2007 son Brasil (60\% de las importaciones argentinas), Japón (7,8\%), Alemania (4,5\%) y EE. UU. (2,64\%). Luego se encuentran México, Francia y China. Salvo Brasil, Argentina compra a los máximos exportadores mundiales.

En definitiva, el déficit de las autopartes se mantiene. Si revisamos en perspectiva ciertos elementos del mercado mundial, que explicaban algunos de los problemas de la actividad en el período previo como la productividad o la escala de producción, encontramos algunas vías para revelar los inconvenientes del complejo (gráficas 19 y 20).

Gráfica 19. Productividad física de la industria automotriz en países seleccionados, vehículos por obrero, 2001-2010

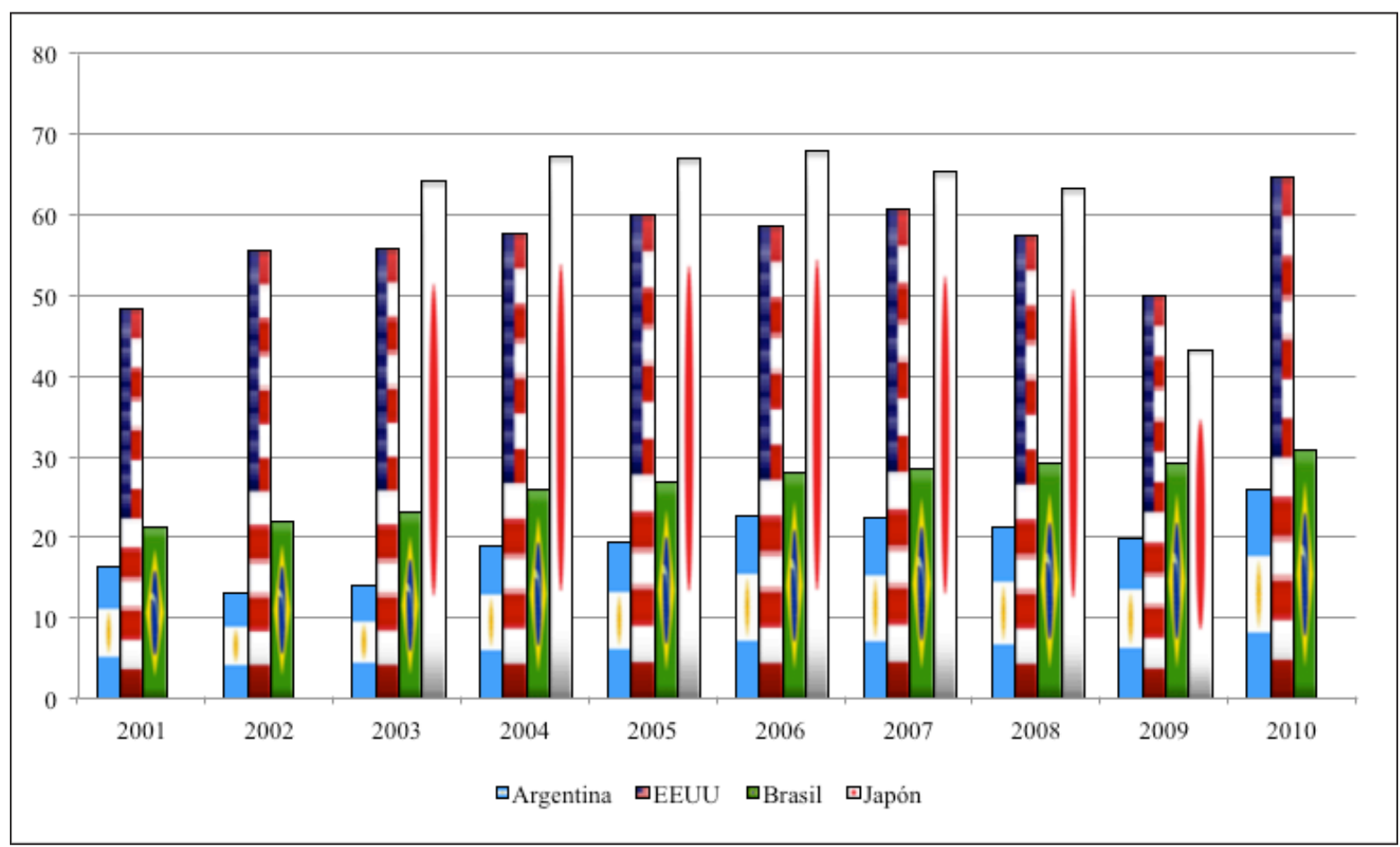

Fuente: elaboración propia con base en información de cámaras de Argentina (Adefa), Brasil (Anfavea) y Japón (Jama) y U.S. Statistical Abstract. 
Gráfica 20. Escala de producción de vehículos en países seleccionados y Argentina; principales industrias automotrices del mundo con locación en Argentina, miles de unidades, 2012

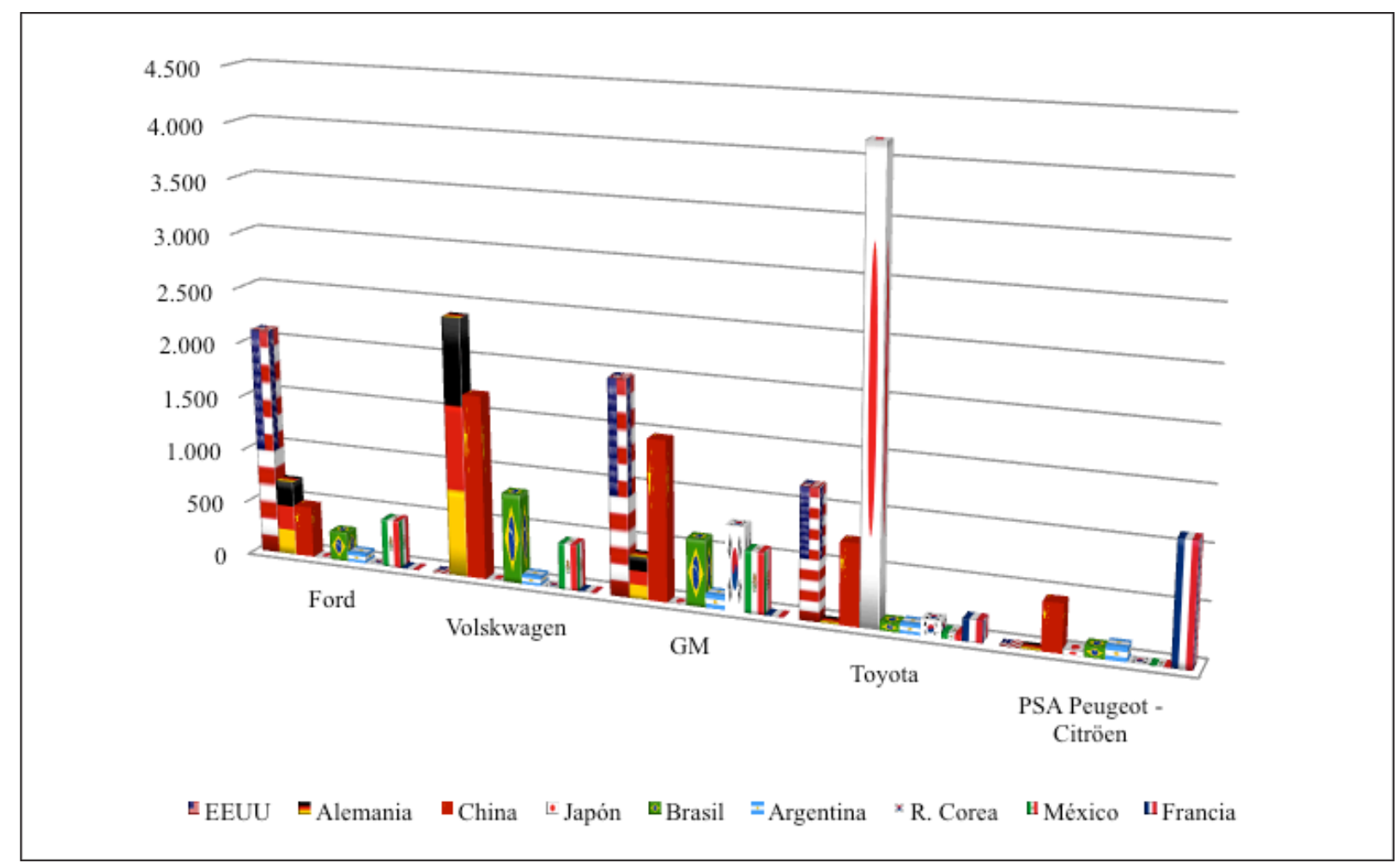

Nota: no se usan datos de Grupo Hyundai (Hyundai-KIA), cuarto productor mundial, por no poseer plantas en Argentina.

De Volskwagen se toman datos de 2011, por no estar desagregados los de 2012.

Fuente: elaboración propia con base en Oica (2013).

Argentina no logró solucionar dos de las dificultades que afectaban al sector, como la menor productividad y la menor escala de producción en relación con los países líderes. Los tradicionales consiguen menores costos unitarios, merced a su escala y productividad mayores; así, pueden elaborar productos terminados más económicos y aumentar su exportación. Para Argentina, ese retraso impide que el autopartismo compense sus mayores costos, e incluso que incorpore la mejor tecnología en plaza, por su imposibilidad de amortizarla. Si bien no contamos aún con el relevamiento de costos del sector, un indicador puede ser el costo laboral en dólares de la manufactura (informado por el Bureau of Labor Statistics de EE. UU). En el autopartismo, los costos se reparten mayormente entre los insumos primarios y la mano de obra. Por ese motivo, puede ser de utilidad lo siguiente: encontramos que Argentina tiene una desventaja en relación con los proveedores con los que puede competir. En 2012, el costo laboral horario argentino fue un 798\% superior al de Filipinas, 196\% al de México, 99\% al de Taiwán, 68,4\% al de Brasil y 57,9\% al de República Checa (cálculo con base en BLS, 2013).

El sector reproduce los problemas históricos, incluso en su época de supuesto esplendor previo (las décadas de los sesenta y setenta). Los déficits no parecen estar vinculados a las políticas públicas. Éstas pueden sostener cierto nivel de actividad o compensar parte de los 
déficits, pero tienen un límite. En momentos de crecimiento económico, el Estado cuenta con mayores recursos para transferir a un sector industrial menos eficiente en relación con la media internacional. Cuando la economía entra en recesión, o cuando el aparato industrial crece más allá de la posibilidad de sostenimiento del Estado, no hay política pública que alcance. El Estado argentino no cuenta con la magnitud de recursos para revertir el panorama.

El problema tampoco se encuentra en la herencia neoliberal o en la "desindustrialización", puesto que el sector arrastra los mismos inconvenientes desde su conformación hacia fines de los cincuenta. Los noventa, por otra parte, fueron el momento en que se inició la recuperación interna de la actividad y que determina la configuración actual del complejo. Por último, es cierto que la nueva división del trabajo reconfiguró la actividad, con el ingreso de nuevos participantes como China o los países del Sudeste Asiático. Estos países se incorporaron a la producción mundial, incluso como líderes, a partir de cambios técnicos. En particular, en la siderurgia, que permitió la incorporación de países con mano de obra barata (Mussi, 2012). Eso se trasladó en varios casos a los encadenamientos "hacia arriba", como el automotor. Los casos chino y surcoreano se explican en gran parte por ello. La "estrategia" de las multinacionales está atada a ese fenómeno; es decir, a priorizar los espacios en los cuales, por los menores costos unitarios, pueden incrementar su tasa de rentabilidad. Expresión de ello es la preocupación de los industriales de autopartes norteamericanos, que presionan por la aplicación de medidas "anti-dumping" debido a que ven su propio mercado cada vez más amenazado por autopartes baratas de China (AAM, 2012). En definitiva, bajo estas relaciones sociales, la solución parece estar en la reducción de los costos unitarios de producción por la vía de la baja del costo laboral. Esto es lo que tiene para ofrecer el capital a los trabajadores en Argentina.

\section{Reflexiones finales}

Repasamos, en perspectiva histórica y en el marco del mercado mundial, la evolución del complejo automotor argentino. Nos centramos en la evolución de su balanza comercial, particularmente de autopartes, y los inconvenientes que la afectaron. Encontramos que, a pesar del entusiasmo oficial, se reiteran los déficits con los que contó el sector históricamente.

Reconstruimos el mercado mundial del complejo en la etapa del mercado protegido, y luego, desde la conformación del Mercosur, y encontramos que los países tradicionales dominaron la exportación. Contaban con un mercado interno amplio, que les permitió sostener una escala adecuada de producción. Desde los noventa, otros que tenían elementos de competitividad como mano de obra barata (que compensaba su menor productividad laboral), también se incorporaron a esta corriente. El desarrollo de un sector terminal moderno en estos espacios les permitió consolidar una industria de autopartes que a su vez — dados la mayor escala, la mejor tecnología incorporada y, por ende, los menores costos- dominó el comercio mundial.

En Argentina, el complejo se desarrolló para proveer al mercado interno, y precisó de transferencias del Estado para subsistir. Si bien sus indicadores crecieron de forma constante, al nivel internacional se amplió la brecha con los países que marcaban la referencia internacional. Los problemas se encontraban en la reducida escala, que se constituyó como una traba para reducir el costo de producción tanto de automóviles terminados como de autopartes. A ello 
se le sumó la menor productividad del trabajo en el país. Estos elementos provocaron que el complejo fuera menos eficiente que los que marcaban la media internacional. El inconveniente de esta situación es que Argentina no contó, históricamente, con factores que le permitieran reducir esta desventaja, como podrían ser insumos económicos o un reservorio de mano de obra barata que posibilitara reducir el costo laboral unitario.

Las autopartes sufrieron en mayor medida esta situación. Mientras que la industria terminal mantuvo, sobre todo desde los noventa, un superávit comercial, las autopartes fueron deficitarias. La suma de ambos sectores arroja un déficit crónico del complejo automotor argentino. Esta situación muestra los problemas de los encadenamientos industriales. En los últimos años no se revirtió. Por el contrario, reproduce el movimiento de la estructura histórica de los encadenamientos en el sector, a pesar de la batería de subsidios que recibió durante los últimos años. No se trata de un problema de políticas o voluntad empresarial. A pesar de las perspectivas optimistas que plantean algunos autores, la cuestión hunde sus raíces en problemas de la estructura productiva. La solución capitalista a la vista, y que pide el empresariado en la prensa desde hace años, parece ser la reducción del costo unitario de producción a partir de la reducción del costo laboral. En la situación actual, parece ser lo único que tiene la burguesía para ofrecer. Lo que, sin dudas, abrirá la perspectiva de nuevos conflictos sociales.

\section{Referencias}

AAM (2012). The Attack on the American Auto Parts Industry. Washington: Alliance for American Manufacturing.

Adefa (1969). La industria automotriz argentina. Buenos Aires: Asociación de Fábricas de Automotores de Argentina.

Adefa (2013). Página web de la Asociación de Fábricas de Automotores de Argentina. En Adefa. Consultado el 01 de febrero, 2014 (http://www.adefa.com.ar/v2/index.php).

Anfavea (2008). Anuário da Indústria Automobilística Brasileira. São Paulo: Associação Nacional dos Fabricantes de Veículos Automotores.

Anuario de Comercio Exterior (varios años). Buenos Aires: Dirección Nacional de Estadísticas.

Baranson, J. (1971). La industria automotriz en los países en desarrollo. Madrid: Tecnos.

Barbero, M. I. y Motta, J. (2007). Trayectoria de la industria automotriz en la Argentina desde sus inicios hasta fines de la década de 1990. En Delfini, M. et al., Innovación y empleo en tramas productivas de Argentina. Buenos Aires: Prometeo, pp. 189-230.

Belini, C. (2006) Negocios, poder y política industrial en los orígenes de la industria automotriz argentina, 1943-1958. Revista de Historia Industrial, 31, pp. 109-138.

BLS (2013). International Comparisons of Hourly Compensation Costs in Manufacturing, 19962012. Time Series Tables. Washington: Bureau of Labor Statistics.

Britos, P. y Fidel, C. (1989). Análisis técnico sobre cajas-puente, semi-ejes y juntas monocinéticas utilizadas en el mercado argentino de automóviles de pasajeros. Buenos Aires: Secretaría de Industria y Comercio Exterior. 
Cantarella, J., Katz, L., De Guzmán, G. (2008). La industria automotriz argentina: limitantes a la integración local de autocomponentes. Buenos Aires: Laboratorio de Investigación sobre Tecnología, Trabajo, Empresa y Competitividad.

CCFA (2012). L'industrie automobile francaise. París: CCFA.

CEP (2013) Centro de Estudios de la Producción. Ministerio de Industria. (http://www.industria.gob.ar/cep/).

Conade (1966). Diagnóstico y proyecciones de la industria siderúrgica. Sector industria y minería. Buenos Aires: Consejo Nacional de Desarrollo, Presidencia de la Nación.

Coudreau, L. y Sorrondegui, H. (editores): Guía Práctica del Exportador e Importador, Buenos Aires (fundada en 1957), varios años.

Frenkel, L. (1992). Juan Ignacio San Martín. El desarrollo de las industrias aeronáuticas y automotriz en la Argentina. Buenos Aires: Germano Artes Gráficas.

García Garnica, A. (2008). Trayectorias de coordinación entre Volkswagen y sus proveedores: las plantas de Brasil, Argentina y México. Análisis Económico, XXIII, 53, pp. 173-200.

Garriz, A. y Soltz, H. (2013). Evolución del comercio exterior en el complejo automotriz argentino (2002-2011). Informe preliminar. Sin publicar..

Harari, I. (2010). ¿Vehículos del imperialismo? La industria automotriz y las deficiencias de la teoría del imperialismo/dependentismo. Razón y Revolución, 20, pp. 29-47.

Harari, I. (2011). Evolución y transformación del proceso de trabajo en la industria automotriz entre 1952 y 1976. Tesis de Doctorado con mención en Historia. Facultad de Filosofía y Letras. Buenos Aires, Universidad de Buenos Aires.

Ianni, V. (2008). La especificidad del desarrollo de la industria automotriz en la Argentina, 19591963. Estudos Ibero-Americanos, XXXIV, 2, pp. 97-113.

Iñigo Carrera, J. (2007). La formación económica de la sociedad argentina. Buenos Aires: Imago Mundi.

Jama (2012). The Motor Industry of Japan. Tokio: J. A. M. A. Inc.

Kornblihtt, J. (2011). Acumulación de capital en Argentina a escala internacional: la producción de tubos sin costura: origen y desarrollo de Siderca (1954-1989). Tesis de Doctorado en Historia. Facultad de Filosofía y Letras, Buenos Aires, Universidad de Buenos Aires.

Kosacoff, B., Todesca, J., Vispo, A.. (1991). La transformación de la industria automotriz argentina. Su integración con Brasil. Buenos Aires: Cepal.

Lifschitz, E. (1982). Comportamiento y proyección de la industria de automotores en América Latina. Los casos de Argentina, Brasil y México. Comercio Exterior, 32 (7), pp. 775-785.

Llach, L. (2011) Maquilladora Automotriz Argentina S. A. En http://blogs.lanacion.com.ar/ciencia-maldita/la-ilusion-y-el-desencanto/maquilladora-automotriz-argentina-sa/, consultado el 6 de junio, 2013.

Maceira, D. (2003). Componente: industria de autopartes. Costos de transacción y competitividad en el sector autopartista argentino. Buenos Aires: CEPAL. 
Manzanelli, P. y Castells, M. J. (2013). ¿La locomotora del desarollo? Algunas reflexiones en torno a la industria automotriz en la Argentina actual. VI Jornadas de Economía Crítica. Mendoza: Universidad Nacional de Cuyo..

Moori-Koenig, V. y Yoguel, G (1992). Competitividad de las PyMEs autopartistas en el nuevo escenario de apertura e integración subregional. Buenos Aires: CEPAL y CFI.

Motta, J., Morero, H., Llinás, I. (2007). Procesos de aprendizaje y de acumulación de conocimiento en las empresas autopartistas argentinas. $12^{\circ}$ Reunión Anual de la Red PYMES, Campinas, Brasil.

Mussi, E. (2012). El desempeño del Estado empresario en la rama siderúrgica a partir de las Memorias y Balances. Una comparación entre Somisa y Posco. XXIII Jornadas de Historia Económica - III Congreso Latinoamericano de Historia Económica, San Carlos de Bariloche.

Novick, M., Rotondo, S., Yoguel, G. (2009). El rol de las políticas públicas en la relación entre tramas locales y cadenas globales: el caso de la industria automotriz en Argentina. Buenos Aires: Observatorio de Empleo y Dinámica Empresarial, Ministerio de Trabajo.

OICA (2013). Production Statistics. International Organization of Motor Vehicle Manufacturers. http://www.oica.net/category/production-statistics/, consultado el 1 de noviembre, 2013.

Oliber, M. (1995). Competitividad y PyMES: autopartes cordobesas. Revista de Economía, 77, pp. 125-181.

ONU (varios años). Industrial Commodity Statistics Yearbook. Nueva York: United Nations.

ONU (varios años). UN Comtrade. http://comtrade.un.org/db/default.aspx

Remes Lenicov, J. (1974). Algunos resultados de la política desarrollista (1958-64): el caso de la industria automotriz. AA. VV.: Problemas económicos argentinos. Diagnóstico y política. Buenos Aires: Macchi, pp. 75-133

Roldán, M. (2000).¿Globalización o mundialización?Teoría de procesos productivos y asimetrías de género. Una interprestación desde las realidades de la organización del trabajo en el apogeo y crisis de una industria nacional autopartista (1960-1990). Buenos Aires: Eudeba.

Romano, F., Giuliano, E., Herrera, S. (2002). Análisis de la competitividad externa regional del sector autopartista. Buenos Aires: Consejo Federal de Inversiones.

Salerno, H., López Conde, M., Mora, P. (1989). Sub-bloque automotriz: evolución 1973-1984 de algunos indicadores censales. Buenos Aires: Secretaría de Industria y Comercio Exterior.

Soria, A. (1989). Conocimiento y proceso de trabajo industrial: análisis del caso de una empresa transnacional productora de autopartes en Argentina, 1948-1987. Buenos Aires: Flacso.

Sourrouille, J. (1980). Trasnacionales en América Latina. El complejo automotor en Argentina. México: Nueva Imagen.

Statistical Abstracts of the United States (varios años). Nueva York: United States Census Bureau.

Wainer, P. (1970). La protección aduanera efectiva en la República Argentina. Reunión Anual de la Asociación Argentina de Economía Política (AAEP), Rosario. 